\title{
Communication and COVID-19 Physical Distancing Behavior Among Dutch Youth
}

\section{ESTHER ROZENDAAL (D) \\ THABO VAN WOUDENBERG (D) \\ EVELINE CRONE (D)}

KAYLA GREEN (D)

\author{
SUZANNE VAN DE GROEP (D) \\ REBECCA DE LEEUW \\ SOPHIE SWEIJEN (1) \\ MONIEK BUIJZEN (1)
}

\section{] $\mathrm{u}$ [ubiquity press}

*Author affiliations can be found in the back matter of this article

\begin{abstract}
Background: Although most young people do not become seriously ill from the coronavirus causing the COVID-19 disease, they do play a role in its spread. It is therefore important that they adhere to the recommended preventive behaviors, most importantly, physical distancing. This study aims to gain a better understanding of the psychosocial determinants of young people's physical distancing behavior and the role that direct (i.e., interpersonal) and mediated communication (i.e., mass media, social media) about COVID-19 plays in this.
\end{abstract}

Methods: A daily diary study was conducted among 481 Dutch adolescents (secondary school students; age range 10-18 years) and 404 young adults (university students; age range 17-25 years), involving 10 identical daily surveys administered on weekdays during a 2-week period during the first wave of the COVID-19 pandemic (May 2020). The hypotheses were tested with preregistered univariate and multivariate linear mixed-effects models.

Results: The perceived descriptive norm (i.e., what friends are doing) was the most important determinant of physical distancing behavior among both adolescents and young adults. The perceived injunctive norm, perceived response efficacy, and perceived severity were also positively associated with physical distancing, albeit less strong. Among adolescents, exposure to information about COVID-19 in the mass media increased their perceptions of the descriptive norm, which in turn increased their physical distancing behavior.

Conclusions: For those involved in studying and designing COVID-19-related behavioral interventions and campaigns targeting youth, it is important to consider the social norms that they relate to, and to take into account their perceived severity and response efficacy.
CORRESPONDING AUTHOR:

\section{Esther Rozendaal}

Erasmus University Rotterdam, $\mathrm{NL}$

rozendaal@essb.eur.nl

\section{KEYWORDS:}

COVID-19; compliance; physical distancing; behavioral determinants; adolescents; young adults

\section{TO CITE THIS ARTICLE:}

Rozendaal, E., van Woudenberg, T., Crone, E., Green, K., van de Groep, S., de Leeuw, R., Sweijen, S., \& Buijzen, M. (2021). Communication and COVID-19 Physical Distancing Behavior Among Dutch Youth. Health Psychology Bulletin, 5(1), pp. 81-102. DOI: https://doi. org/10.5334/hpb.33 
Although most young people do not become seriously ill from the COVID-19 virus, they do play an important role in spreading the coronavirus. If they become infected, they run the risk of infecting others including those who are more vulnerable, such as the elderly and the chronically ill. It is, therefore, highly important that young people prevent themselves from becoming infected and infecting others by adhering to the recommended COVID-19 preventive behaviors.

One of the most important behavioral measures to prevent virus transmission recommended by experts and public health organizations, including the World Health Organization, is physical distancing (Anderson et al., 2020). Physical distancing, sometimes referred to as social distancing, means keeping a safe space ( 1,5 meter) between yourself and other people who are not from your household (Chu et al., 2020). Physical distancing behavior is different from many other health preventive behaviors, among other things because individual behaviour generates outcomes not only for the individual concerned, but also for others around them and wider society. In other words, individuals are engaged in a collective action problem or social dilemma where selfish and collective interests may not be aligned (Johnson et al., 2020; Kollock, 1998; Teck Ling \& Chyong Ho, 2020).

To mitigate the COVID-19 pandemic, crisis teams, policymakers, and communication professionals face the challenge to educate young people about the usefulness and necessity of physical distancing behavior, and convince them to comply to this measure even if they feel the behavior is not in their own interest. To do so effectively, more insights are needed into the factors that explain the physical distancing behavior of young people. The current study aims to provide such insights, which can then be used to guide future research in examining young people's physical distancing behavior and may aid in the development of effective COVID-19 communication campaigns and interventions.

Given the importance of human behavior in mitigating the spread of the virus, several researchers and policymakers have already pointed to the relevance of the social and behavioral sciences in this pandemic (Bavel et al., 2020; Lunn et al., 2020). The current study adopts a behavioral science approach by examining the role of different psychosocial determinants in shaping the physical distancing behavior of young people. In addition, this study explores the role of mediated and interpersonal communication about COVID-19. During the COVID-19 pandemic, an extensive amount of information related to the coronavirus is disseminated by mass media, social media, and interpersonal communication (Lin et al., 2020). Insights from the health communication literature suggest that exposure to information about health risks and recommended coping behaviors can affect people's health behavior (Hornik, 2002). However, to date, insights into the relation between exposure to information about
COVID-19 and physical distancing behavior among young people is still lacking.

Therefore, the aim of this study is to better understand young people's physical distancing behavior during the COVID-19 pandemic by investigating the psychosocial and communication-related determinants of this behavior. Specifically, we examine how (1) psychosocial factors (i.e., perceived threat, perceived coping efficacy, perceived social norms) and (2) exposure to communication about the coronavirus via mass media, social media, and interpersonal contact relate to young people's physical distancing behavior and (3) whether psychosocial determinants mediate the relation between exposure to communication and behavior. The study addresses this aim with a daily diary study among Dutch adolescents (secondary school pupils; age range 10-18 years) and young adults (university students; age range $17-25$ years), involving 10 identical daily surveys administered on weekdays during a 2-week period in May 2020, a few months after the start of the COVID-19 pandemic.

\section{PSYCHOSOCIAL DETERMINANTS OF YOUNG PEOPLE'S PHYSICAL DISTANCING BEHAVIOR}

To gain more insight into the factors that determine young people's physical distancing behavior during the COVID-19 pandemic, this study draws on socialpsychological theory explaining what drives people to engage in health-related behaviors, more specifically, the Health Belief Model (Glanz et al., 2015), the Protection Motivation Theory (Rogers, 1975; Witte, 1992), and Social Cognitive Theory (Bandura, 1986; Rosenstock et al., 2016). Based on these theories, we focus on three sets of determinants. According to the first two theories, the decision to engage in a certain behavior is governed by two distinct cognitive processes: perceptions of the threat and perceptions of the efficacy of the recommended coping behavior. In addition, according to Social Cognitive Theory, perceptions of social norms importantly steer behavior.

\section{PERCEIVED THREAT}

Perceived threat involves the perceptions of the magnitude and immediacy of danger, in this case being infected with the coronavirus disease and to infect others. The perceived threat includes the perceived severity of and the perceived susceptibility to the threat. Perceived severity involves an individual's belief about the seriousness of the threat (Witte, 1992). In the current study, perceived severity is conceptualized as the extent to which young people believe the spread of the coronavirus is a problem. This perception of severity is important, because young people who do not believe 
the spread of the virus is a problem will be less motivated to engage in the preventive physical distancing behavior. Perceived susceptibility involves an individual's belief about his or her chance of experiencing the health threat (Witte, 1992). In the current study, perceived susceptibility is conceptualized as the extent to which young people feel they run the risk of getting infected by the COVID-19 virus themselves and, in turn, infect others. This perception of susceptibility is important, because when people do not feel that they can become infected by the virus or infect others, they will be less motivated to engage in physical distancing behavior, even when the threat itself is very serious.

Earlier research has shown that perceived threat (including perceived severity and susceptibility) influences behavior in many health contexts, such as vaccination, diet, exercise, smoking cessation, and contraception (Bish \& Michie, 2010; Donadiki et al., 2014; Glanz et al., 2015; Kloeblen \& Batish, 1999; Koch, 2002; Mantler, 2013; Nexøe et al., 1999). Recent research among adults shows that perceived threat is also a key determinant of preventive behavioral engagement in the context of COVID-19, such as information seeking (Park et al., 2020) or engaging in protective behaviors including hand washing, hand sanitizing, physical distancing, selfquarantining, disinfecting, mask-wearing (Kowalski \& Black, 2021)). Therefore, we formulate the following hypothesis:

H1: Higher levels of (a) perceived severity of the spread of the COVID-19 virus and (b) perceived susceptibility to the COVID-19 virus threat are related to more physical distancing behavior.

\section{PERCEIVED EFFICACY}

Prevailing health behavior theories postulate that behaviour change is the function of a perceived threat, but only when there is sufficient perceived efficacy (Witte, 1992). Perceived efficacy of a protective behavior includes an individual's evaluations of response efficacy and self-efficacy. Response efficacy is the belief that engaging in a certain behavior will result in the reduction of a health threat (Witte, 1992). This perception of efficacy is important, because people will usually not establish protecting behavior if they do not believe that this behavior is effective or beneficial (Rogers, 1975). In the context of the current study, response efficacy is conceptualized as the feeling that physical distancing is an effective way to avoid getting infected by the COVID-19 virus or infecting others with the virus. Selfefficacy is a person's belief in his or her own ability to carry out the recommended behavior (Glanz et al., 2015). People who believe in their capability to engage in protective behavior are assumed to be more likely to engage in the behavior than those with low selfefficacy (Rosenstock et al., 2016). In the current study, self-efficacy is conceptualized as young people's belief in their ability to keep a physical distance of 1.5 meters from others.

Earlier research has shown that perceived efficacy (including perceived response efficacy and perceived self-efficacy) influences protective health behavior in many other health contexts, such as condom use, blood donation, smoking cessation, and physical activity (Bish \& Michie, 2010; Glanz et al., 2015; Sheeran et al., 2016). More recent research has shown that both types of perceived efficacy predict engaging in protective behaviors (Kowalski \& Black, 2021). Therefore, we formulate the following hypothesis:

H2: Higher levels of (a) perceived response efficacy and (b) perceived self-efficacy are related to more physical distancing behavior.

\section{PERCEIVED SOCIAL NORMS}

People's decision to engage in certain health behaviors does not occur in a vacuum, but also depends on their social context (Bavel et al., 2020; Chan et al., 2020). According to Social Cognitive Theory (Bandura, 1986, 2004; Rosenstock et al., 2016) people's behavior is influenced by their social environment, importantly, by the social norms in their environment. Perceived social norms are people's perceptions of what others are doing (i.e., descriptive norm) and of what they think others approve of or not (i.e., injunctive norm (Cialdini \& Goldstein, 2004). Young people are highly reactive to the behaviors and opinions of others, especially their friends and other peers (Valkenburg \& Piotrowski, 2017). They tend to adopt values, motives and behaviors that they perceive as normative within their group of friends or other peers they identify with. Also, physical distancing behavior typically takes place in social contexts, and the choice whether to keep a distance (or in other words, whether you adhere to the norm) is therefore highly visible to others. Moreover, physical distancing behavior can be seen as a collective action problem in which individuals typically only tend to cooperate when they believe that others are also likely to cooperate (Bolsen et al., 2014; Frey \& Meier, 2004). Taken together, this suggests that social norms may play an important role in determining the successful performance of physical behavior among young people. In the current study, descriptive social norms are conceptualized as young people's perceptions of how often their friends keep a 1.5 meters distance from others. Injunctive social norms are conceptualized as young people's perceptions of whether their friends think that he or she ought to keep 1.5 meters away from others.

Earlier research has shown that social norms (both injunctive and descriptive) influence behavior in many other health contexts, such as diet, exercise, and smoking cessation (Sheeran et al., 2016). Preliminary evidence in 
the context of COVID-19 also shows that social norms are a crucial determinant of people's engagement in a broad set of COVID-19 preventive behaviors, including physical distancing (Goldberg et al., 2020). Therefore, we formulate the following hypothesis:

H3: Higher levels of (a) injunctive and (b) descriptive norms are related to more physical distancing behavior.

\section{COMMUNICATION ABOUT COVID-19 AND PHYSICAL DISTANCING BEHAVIOR}

People's decision to engage in a recommended health behavior can be influenced by external stimuli or sources of information, such as media messages and interpersonal communication about the health threat and the recommended behavior (Glanz et al., 2015; Hong \& Kim, 2020; Witte, 1992). In the current study, we investigate the role of the level of exposure to various types of communication about COVID-19, the role of valence of affective responses to the various types of communication, and behavioral responses to press conferences.

\section{LEVEL OF EXPOSURE TO COVID-19 COMMUNICATION}

We focus on three types of communication: mass media communication, social media communication, and interpersonal communication. During the COVID-19 pandemic, mass media communication channels such as television, radio, newspaper, news apps, and websites are being used extensively by the government, health organizations, and journalists to share information about COVID-19 and specifically about physical distancing as one of the recommended behaviors to combat the virus. Information about COVID-19 and physical distancing is also shared via social media platforms (e.g., Twitter, Facebook, Instagram, TikTok), and via interpersonal communication. When talking about COVID-19 with others directly, young people not only receive information about their take on the COVID-19 crisis and the behavioral measures, but also experience directly how others deal with the 1.5-meter distance measure.

Arecentstudy amongyounger and older adults (aged 18 to 60 years) in China indeed provides preliminary evidence that the consumption of COVID-19-related information on various digital media could prompt preventive behaviors (Liu, 2020). Based on these preliminary results and earlier research on health communication in other contexts, we expect that exposure to information about COVID-19 can directly trigger young people to engage in physical distancing behavior. Therefore, we formulated the following hypothesis:
H4: A higher level of exposure to communication about COVID-19 (via mass media, social media, and interpersonal communication) is related to more physical distancing behavior.

Besides directly triggering people to perform the recommended health behavior, exposure to mediated and interpersonal health communication can also indirectly stimulate them to do so by changing the behavioral determinants: perceived threat, perceived efficacy, and social norms. That is, the exposure to communication about COVID-19 can affect people's perception of the virus and inform individuals what others are doing. We expect that increased exposure to communication about COVID-19, increases the chance of being exposed to information about the number of infections, hospitalizations, and deaths. This could affect young people's perceptions of the severity of the virus and their perceived susceptibility to the virus. Communication about COVID-19 could also provide information about the extent to which physical distancing helps to not get infected or infect others, which could increase the perceived efficacy of physical distancing as a coping behavior. Finally, communication about COVID-19, in particular when shared via social media and interpersonal communication, can provide information about what others are doing (e.g., do others comply with the physical distancing rule?) and what others approve and disapprove of (e.g., do others feel it's important to keep the 1.5-meter distance?), which can alter both the descriptive and injunctive social norm. Taken together, we hypothesize that:

H5: The relations between the level of exposure to communication about COVID-19 and physical distancing behavior (see H4) are mediated by (a) perceived severity, (b) perceived susceptibility, (c) perceived efficacy, (d) injunctive norms, and (e) descriptive norms.

\section{AFFECTIVE RESPONSES TO COVID-19 COMMUNICATION}

Theories in social psychology suggest that people's feelings act as a form of information that they refer to when deciding whether or not to engage in particular health behaviors (E. Peters et al., 2006; Schwarz, 2012; Storbeck \& Clore, 2008). This is also referred to as the affect-as-information hypothesis (Storbeck \& Clore, 2008). If people experience negative affect, such as fear, this can stimulate people's decision to engage in the health behavior as it sensitizes them to risks for themselves or others (Harper et al., 2020; Loewenstein et al., 2001; Slovic et al., 2004). However, strong negative emotional reactions could also paralyze people and distract them from performing the desired behavior (Witte, 1992). Thus, negatively valenced affective 
responses to communication can stimulate behavior, provided that the experience is not too negative. However, positively valenced affective responses to communication could trigger the desired behavior as well. Research in the field of positive media psychology shows that positive feelings elicited by media communication (such as awe, gratitude, elevation) can inspire people to take action, for example by acting more prosocially toward others (Coyne et al., 2018; Janicke-Bowles et al., 2019). This typically occurs when people are exposed to media content portraying humanity's better nature: altruism, kindness, compassion, perseverance, and love (Janicke-Bowles et al., 2019), examples of which often appeared in media during the first wave of the pandemic.

Therefore, in the current study we assume that both negative and positive feelings that young people experience when encountering COVID-19 information in the mass media, on social media, or via interpersonal communication can impact their physical distancing behavior. We formulate the following research question:

RQ1: To what extent does the valence of youth's affective responses to communication about COVID-19 affect the relation between exposure to communication about COVID-19 and physical distancing behavior?

\section{GOVERNMENT COVID-19 PRESS CONFERENCES AS A CALL FOR ACTION}

In addition to information about a health threat via mediated and interpersonal communication, specific events can promote engagement in health-related behaviors (Glanz et al., 2015). Therefore, we also investigate the extent to which governmental press conferences affect young people's physical distancing behavior. In the country of this study, government press conferences involved the primary way to inform the public about the current COVID-19 situation and regulations. The conferences are prime time media events, which are followed by a large share of the public. During our data collection period, there were two important government press conferences. In the first one, at May 6 , the prime minister presented a 'road map' containing the gradual phasing out of the strict lockdown measures (e.g., reopening primary schools, contact professions back to work, outdoor sports allowed). In the second press conference, on May 19, the prime minister presented a further relaxation of the lockdown (e.g., reopening secondary schools, restaurants, bars, museums, cinemas, theaters, etc.). The second press conference is particularly interesting because the Prime Minister directly addressed young people and called on them to come up with ideas on how to tackle the corona crisis. To explore whether the press conferences functioned as a call for action, we formulate the following research question:
RQ2: To what extent did the government COVID-19

press conferences in May 2020 affect young

people's physical distancing behavior?

\section{METHODS \\ PARTICIPANTS}

We used two distinct samples: a school sample of adolescents in secondary schools and a university sample of young adults. Both samples were analyzed separately. For the school sample, participants were recruited in five secondary schools in Rotterdam, the Netherlands. The adolescents in the schools were contacted via their dean or teacher and 485 adolescents had parental consent to participate in the study. Four participants were excluded from the sample because they did not meet de preregistered inclusion criteria for the maximum age of 18 years. Participants in the school sample $(n=481)$, were between 10 and 18 years old $\left(M_{\text {Age }}=14.80, S D_{\text {Age }}=\right.$ $1.81,34.27 \%$ male).

In the university sample, participants were recruited from the Erasmus University Rotterdam. The students were contacted via an email sent to all students, via social media channels of the university (i.e., Instagram, Twitter, and Facebook), and via the student well-being platform of the university ('Are you OK out there'). In response, 441 students provided consent to participate in the study. Of those, 37 participants were excluded from the sample because they did not meet de preregistered inclusion criteria for the maximum age of 25 years old or were not students (anymore) at the university. Participants in the university sample $(n=404)$, were between 17 and 25 years old $\left(M_{\text {Age }}=21.01, S D_{\text {Age }}=\right.$ $1.93,18.09 \%$ male).

\section{DESIGN AND PROCEDURE}

The data collection was part of a larger project investigating young people's well-being during the COVID-19 pandemic. An overview of all the studies and measured variables in the project can be found at the Open Science Framework (OSF): https://osf.io/ nh2ak/. The hypotheses, measured variables, and plan of analysis were preregistered before gaining access to the data and can be found at https://osf.io/aez5h/?view only=fc7643d36c644ffab178360906488e6e. Also, when writing the manuscript, we adhered to the Strengthening The Reporting of Observational Studies in Epidemiology (STROBE) checklist (von Elm et al., 2014).

The study used a daily diary study in which participants received 10 identical daily questionnaires administered via Qualtrics on weekdays for 2 weeks. Participants could fill out the digital questionnaires on a computer or other device connected to the internet (e.g., smartphone, tablet, laptop). Both samples had two starting points, resulting in two batches in each sample. Participants in the first batch were measured from May $4^{\text {th }}$ until May 
$15^{\text {th }}, 2020$. The second batch started a week later, and participants were measured from May $11^{\text {th }}$ until May $22^{\text {nd }}$, 2020. In the country of data collection, this was at the end of the first lockdown, when schools and universities were still closed. Each day, participants were reminded at noon (12:00 am) via email and received a reminder via text message at 8:00 pm to fill out the questionnaire. On the first, the fifth, and the last day, they received additional questions, for example on their demographic background.

\section{MEASURES}

\section{Physical distancing}

Physical distancing was measured by two items. The first measured how often participants over the past 24 hours had tried to keep 1.5 meters distance from others (regardless of whether these others came from their own or another household) on a 6-point scale, ranging from never (1) to all the time (6). Participants could also indicate that this question was not applicable (7) and was recoded into ' $N A$ '. The second item measured, on the same 6-point scale, how often participants over the past 24 hours had succeeded in keeping 1.5 meters distance from others. A mixed-effects correlation, with a random intercept per participant, between the two items in the combined sample was high $(r=.63, \mathrm{SE}=.01, p<.001)$. Following the preregistration, the physical distancing variable was therefore calculated by averaging the two items. Not all respondents answered the questions each day, on average participants responded to the physical distancing question on 6.67 (SD = 2.81) of the 10 days. Table 1 presents an overview of the means, standard deviations, and range of the physical distancing variable as well as all the other variables in the school and the university sample.

\section{Psychosocial determinants}

We measured five psychosocial determinants of physical distancing behavior: perceived severity, perceived susceptibility, response efficacy, descriptive norm, and injunctive norm. Due to a technical error, self-efficacy was not included in the daily questionnaires and, consequently, could not be included in the planned analyses.

\section{Perceived severity}

Perceived severity was measured by asking participants the question: "At this moment, do you think the spread of the coronavirus is a problem?" on a 6-point scale, ranging from no, definitely not (1) to yes, definitely (6).

\section{Perceived susceptibility}

For this variable, participants were asked: "At this moment, do you think that you can become contaminated with the coronavirus, and in that way contaminate others?" on a 6 -point scale, ranging from no, definitely not (1) to yes, definitely (6).

\section{Response efficacy}

To measure response efficacy, participants responded to the question: "At this moment, do you think that by keeping 1.5 meters physical distance you will reduce the spread of the coronavirus?" on a 6-point scale, ranging from never (1) to always (6).

\section{Perceived descriptive norm}

The perceived descriptive norm was measured by asking participants the question: "How often do you think that, in the past 24 hours, your friends kept 1.5 meters physical distance from others?" on a 6 -point scale, ranging from never (1) to all the time (6).

\begin{tabular}{lcccccccc}
\hline \multirow{2}{*}{ VARIABLE } & \multicolumn{3}{c}{ SCHOOL SAMPLE (N = 481) } & \multicolumn{3}{c}{ UNIVERSITY SAMPLE (N = 404) } \\
\cline { 2 - 9 } & MEAN & SD & MIN & MAX & MEAN & SD & MIN & MAX \\
\hline Physical distancing & 4.56 & 0.97 & 1.08 & 6.00 & 4.74 & 0.89 & 1.75 & 6.00 \\
\hline Perceived severity & 5.11 & 0.88 & 1.00 & 6.00 & 5.14 & 0.84 & 1.00 & 6.00 \\
\hline Perceived susceptibility & 4.76 & 1.15 & 1.00 & 6.00 & 4.80 & 1.07 & 1.00 & 6.00 \\
\hline Response efficacy & 4.57 & 1.18 & 1.00 & 6.00 & 4.84 & 0.98 & 1.00 & 6.00 \\
\hline Descriptive norm & 3.90 & 1.17 & 1.00 & 6.00 & 4.16 & 1.14 & 1.00 & 6.00 \\
\hline Injunctive norm & 3.50 & 1.52 & 1.00 & 6.00 & 4.18 & 1.29 & 1.00 & 6.00 \\
\hline Mass media & 2.32 & 0.79 & 1.00 & 4.00 & 2.32 & 0.73 & 1.00 & 4.00 \\
\hline Mass media valence & 3.97 & 1.07 & 1.00 & 7.00 & 4.19 & 0.92 & 1.00 & 7.00 \\
\hline Social media & 1.82 & 0.55 & 1.00 & 4.00 & 2.00 & 0.62 & 1.00 & 4.00 \\
\hline Social media valence & 4.23 & 1.07 & 1.00 & 7.00 & 4.33 & 0.86 & 1.00 & 7.00 \\
\hline Interpersonal communication & 1.93 & 0.56 & 1.00 & 4.00 & 2.06 & 0.61 & 1.00 & 4.00 \\
\hline Interpersonal communication valence & 4.16 & 1.04 & 1.10 & 7.00 & 4.30 & 0.88 & 1.00 & 7.00 \\
\hline
\end{tabular}

Table 1 Descriptives of Main Variables for the School and University Sample. 


\section{Perceived injunctive norm}

The perceived injunctive norm was measured by asking participants the question: "Do you think that, in the past 24 hours, your friends believed that you should keep 1.5 meters physical distance from others?" on a 6-point scale, ranging from no, definitely not (1) to yes, definitely (6).

\section{Communication-related determinants}

The participants' exposure to information about COVID-19 was measured with a single item for each type of communication.

\section{Mass media communication}

The exposure to information about COVID-19 consumed on mass media was measured with the question "In the past 24 hours, how much did you see or hear about the coronavirus on other types of media (e.g., television, radio, newspapers, news apps, or websites)?" on a 4-point scale, ranging from nothing (1) to a lot (4).

\section{Social media communication}

The exposure to information about COVID-19 consumed on social media was measured with the question "In the past 24 hours, how much did you see or hear about the coronavirus on social media (e.g., Instagram, WhatsApp, Snapchat, YouTube, Facebook, TikTok)?" on the same 4-point scale.

\section{Interpersonal communication}

The exposure to information about COVID-19 via interpersonal communication was measured with the question "In the past 24 hours, how much did you see or hear about the coronavirus of people that you were talking to directly (e.g., friends, parents, or teachers)?" on the same 4-point scale.

\section{Valence}

For each of the three types of communication, the corresponding valence of affective response was measured. Directly after the specific media question, participants were shown seven pictures of faces ranging from a very sad face (1) to a very happy face (7) and were asked to select the face that best matched how they felt about the communication they had been exposed to.

\section{Covariates}

In the preregistration, we anticipated several covariates that should be controlled for in the analyses. The sex and age variables were measured on the first day. The categorical variable sex was recoded by using contrast coding so that the difference between females (-.5) and males (.5) was exactly 1 , and the age (in years) variable was centered per sample so that the intercept represented the mode of the age in the sample and the average of females and males. In the school sample the mode was 15 years old, and in the university sample 23 years old. Socioeconomic status was also preregistered as a covariate, but it was unfortunately not measured and could not be included in the analyses.

Also, two time-related variables were preregistered as covariates of the developments of physical distancing over time. Both the week of the measurement (week 1 vs week 2) and the day of the week (1-5, in which the first day is a Monday) were added as covariates to control for a potential change in behavior between the two weeks or within the weeks.

After the preregistration, we realized that other factors might affect physical distancing. More specifically, we deemed it important to control for potential weather effects. For example, with higher temperatures and dry weather, participants would go outside more often, potentially having a harder time keeping a physical distance from others and using less mass media, whereas they would be more likely to stay at home when it was colder and raining. Therefore, the mean temperature and hours of precipitation per day in Rotterdam, the Netherlands during the measurements were taken from the website of the Royal Netherlands Meteorological Institute (Royal Netherlands Meteorological Institute, 2020). In addition, we controlled for a pilot behavioral boosting task that was offered as an option to a subsample of participants in the middle of the measurement period and which might have affected their physical distancing behaviors in the second week. The behavioral boosting task consisted of two subtasks: a self-persuasion task in which participants had to write down two reasons why they should keep a distance of 1.5 metres from others and an implementation intention task in which participants had to write down a plan for what they could do if were are in a situation in which they could not manage to keep a distance of 1.5 metres from others (e.g., if-then plan; (Gollwitzer, 1999; Hertwig \& Grüne-Yanoff, 2017; Müller et al., 2009).

\section{STRATEGY OF ANALYSIS}

In the preregistration, we indicated that the preferred strategy to test the hypotheses was to use Bayes mixedeffects models. However, the BayesFactor package that we would use for this does not allow for missing values. As a result, we would only be able to include 1,826 of the 4,810 observations in the school sample and 1,411 of the 4,040 observations in the university sample. Therefore, we opted for the preregistered alternative and used NHST mixed-effects modeling in the Ime4 package (Bates et al., 2014) in R (R Core Team, 2019). Standard Errors (SE), confidence intervals, degrees of freedom, and $p$-values were computed using Satterthwaite approximation (Satterthwaite, 1946), and confidence intervals not including 0 and $p<.05$ was considered statistically significant. To test the robustness of the mixed-effects models, a robust mixed-effects model, by using the rlmer 
function in the robustlmm package (Koller, 2016), was estimated with all predictors included to inspect different parameter estimates and outcomes.

Before conducting the main analyses, we first tested the additional, non-preregistered, covariates. First, we modeled the mean temperature per day and the hours of rain per day in univariate mixed-effects models with physical distancing as the outcome variable and random intercepts per participant in a combined sample. Only the mean temperature per day was significantly associated with physical distancing $(B=-.02, S E=.002, t=-5.884$, $p<.001$ ) and, therefore, added to the preregistered covariates. Then, we tested the potential confounding effect of the pilot behavioral boosting task. The differences between the groups in the change of behavior from the first to the second week were tested with two planned contrasts distinguishing whether participants received the additional questionnaire (yes vs. no) and whether the participant took part in the behavioral boosting pilot (accepting vs. declining). Both planned contrasts showed no interaction with the week variable, indicating that there were no differences between the groups in the change in physical activity behavior between the first and the second week. Therefore, we did not control for exposure to the behavioral boosting questionnaire.

To test hypotheses $1-3$, a multivariate linear mixedeffects model was specified with physical distancing as the dependent variable, the psychosocial behavioral determinants (i.e., perceived severity, perceived susceptibility, response efficacy, descriptive norm, injunctive norm), and the covariates as predictors, and random intercepts per participant.

To test hypothesis 4, a multivariate linear mixedeffects model was specified with physical distancing as the dependent variable, the three communication types (i.e., social media, mass media, interpersonal communication) and the covariates as predictors, and random intercepts per participant. To provide insight into the role of each of the studied psychosocial determinants and communication types separately, all studied relations were also tested in univariate models, only including the focal predictor, the covariates, and random intercepts per participant. These univariate results are needed to inform future intervention research and provide guidance on which determinants to select and target in an intervention stimulating the desired behavior (Crutzen \& Peters, 2020).

To test hypothesis 5, the total relation of the communication types on physical distancing behavior was split into the direct relation and the indirect relation between the communication types and physical distancing behaviors mediated by the psychosocial determinants. Both relations were estimated simultaneously in the mlma package for multi-level mediation (Yu \& Li, 2020a, 2020b), however, without the covariates. Statistical relevance of the paths was determined based on bootstrapped confidence intervals and we established mediation when the confidence interval of the indirect relation via one of the psychosocial determinants did not include 0 . Furthermore, if the direct relation holds, we conclude partial mediation and when the direct relation is not statistically significant, we conclude that the psychosocial determinants fully mediates the relation.

Finally, addressing the exploratory research questions, we investigated the moderating role of the valence of affective responses to communication (RQ1) using the same model as in hypothesis 4, with the addition of an interaction term for the standardized score for each type of communication and the respective standardized valence of affective response. Significant interactions were plotted for interpretation of the different slopes.

To analyze the behavioral impact of the government COVID-19 press conferences (RQ2), we specified a similar multivariate linear mixed-effects model with physical distancing as the dependent variable, random intercepts per participant, the preregistered and temperature covariates, and a dummy variable that coded whether a COVID-19 press conference took place on that day (and a second dummy for the day after the press conferences) was added to the model. Also, we explored whether there was a linear decline in adherence to the regulations by using the same model but changing the press conference dummy for a continuous variable that measured the number of days since the last press conference.

First, we investigated whether adolescents and young adults would be more likely the keep physical distance on the day of the national press conferences. We created a dummy variable that marked both dates on which there was a national press conference. A second dummy variable marked both dates of the days after the national press conferences. Again, linear mixed-effects models were used in which physical distancing was predicted by the dummy variable and the covariates, and random intercept per participant.

\section{RESULTS \\ THE RELATIONS BETWEEN PSYCHOSOCIAL DETERMINANTS AND PHYSICAL DISTANCING BEHAVIOR (H1-H3)}

The fixed effects in multivariate model testing hypotheses 1 to 3 explained $44 \%$ of the variance in physical distancing in the school sample and 35\% in the university sample (marginal $\mathrm{R}^{2}$ ). The proportion of variance explained by both fixed and random effects was 69\% in the school sample and $66 \%$ in the university sample (conditional $\mathrm{R}^{2}$ ). As can be seen in Table 2, the perceived severity of the spread of the COVID-19, the perceived response efficacy, and both the descriptive and injunctive norm significantly related to physical distancing in the school sample. 


\begin{tabular}{|c|c|c|c|c|c|c|c|c|}
\hline \multirow[t]{2}{*}{ VARIABLE } & \multirow[t]{2}{*}{ B } & \multicolumn{2}{|c|}{$95 \%$ CI FOR B } & \multirow[t]{2}{*}{ SE } & \multirow[t]{2}{*}{$\beta$} & \multirow[t]{2}{*}{$D F$} & \multirow[t]{2}{*}{$T$} & \multirow[t]{2}{*}{$P$} \\
\hline & & $L L$ & $U L$ & & & & & \\
\hline Intercept & 2.16 & 1.84 & 2.48 & 0.16 & & 1297.77 & 13.40 & $<.001$ \\
\hline Perceived severity & 0.05 & 0.00 & 0.10 & 0.02 & 0.05 & 1760.84 & 2.14 & 0.032 \\
\hline Perceived susceptibility & 0.03 & -0.01 & 0.08 & 0.02 & 0.03 & 1639.10 & 1.54 & 0.123 \\
\hline Response efficacy & 0.08 & 0.04 & 0.12 & 0.02 & 0.09 & 1581.00 & 4.05 & $<.001$ \\
\hline Descriptive norm & 0.42 & 0.39 & 0.46 & 0.02 & 0.49 & 1803.12 & 24.61 & $<.001$ \\
\hline Injunctive norm & 0.07 & 0.04 & 0.10 & 0.02 & 0.10 & 1665.07 & 4.62 & $<.001$ \\
\hline Sex (Male) & -0.13 & -0.27 & 0.02 & 0.07 & -0.05 & 344.75 & -1.73 & 0.084 \\
\hline Age & -0.02 & -0.06 & 0.01 & 0.02 & -0.04 & 357.68 & -1.27 & 0.206 \\
\hline Mean temperature & 0.00 & -0.01 & 0.01 & 0.00 & 0.00 & 1623.29 & -0.05 & 0.959 \\
\hline Week & -0.21 & -0.28 & -0.14 & 0.04 & -0.09 & 1602.70 & -5.94 & $<.001$ \\
\hline Day & -0.05 & -0.07 & -0.03 & 0.01 & -0.06 & 1587.39 & -4.73 & $<.001$ \\
\hline
\end{tabular}

Table 2 Multivariate Linear Mixed-Effects Model Predicting Physical Distancing Behavior in the School Sample. Note: $N=375$. $\mathrm{ICC}_{\text {Participant }}=.46$. Marginal $\mathrm{R}^{2}=.44$. Conditional $\mathrm{R}^{2}=.69$.

\begin{tabular}{|c|c|c|c|c|c|c|c|c|}
\hline \multirow[t]{2}{*}{ VARIABLE } & \multirow[t]{2}{*}{ B } & \multicolumn{2}{|c|}{$95 \%$ CI FOR B } & \multirow[t]{2}{*}{ SE } & \multirow[t]{2}{*}{$\beta$} & \multirow[t]{2}{*}{$D F$} & \multirow[t]{2}{*}{$T$} & \multirow[t]{2}{*}{$P$} \\
\hline & & $L L$ & $U L$ & & & & & \\
\hline Intercept & 1.91 & 1.47 & 2.35 & 0.23 & & 1008.75 & 8.45 & $<.001$ \\
\hline Perceived severity & 0.04 & -0.01 & 0.10 & 0.03 & 0.04 & 1374.41 & 1.50 & 0.133 \\
\hline Perceived susceptibility & 0.01 & -0.04 & 0.06 & 0.03 & 0.01 & 1291.87 & 0.24 & 0.810 \\
\hline Response efficacy & 0.14 & 0.09 & 0.20 & 0.03 & 0.14 & 1191.50 & 5.02 & $<.001$ \\
\hline Descriptive norm & 0.40 & 0.36 & 0.44 & 0.02 & 0.46 & 1401.92 & 19.32 & $<.001$ \\
\hline Injunctive norm & 0.05 & 0.01 & 0.09 & 0.02 & 0.06 & 1336.88 & 2.48 & 0.013 \\
\hline Sex (Male) & -0.02 & -0.22 & 0.17 & 0.10 & -0.01 & 268.17 & -0.23 & 0.816 \\
\hline Age & -0.04 & -0.08 & 0.01 & 0.02 & -0.06 & 289.86 & -1.66 & 0.097 \\
\hline Mean temperature & -0.01 & -0.02 & 0.00 & 0.01 & -0.02 & 1233.40 & -1.36 & 0.174 \\
\hline Week & -0.08 & -0.16 & 0.00 & 0.04 & -0.03 & 1226.20 & -2.04 & 0.041 \\
\hline Day & 0.00 & -0.03 & 0.03 & 0.01 & 0.00 & 1215.35 & 0.08 & 0.936 \\
\hline
\end{tabular}

Table 3 Multivariate Linear Mixed-Effects Model Predicting Physical Distancing Behavior in the University Sample.

Note: $N=305$. $\mathrm{ICC}_{\text {Participant }}=.47$. Marginal $\mathrm{R}^{2}=.35$. Conditional $\mathrm{R}^{2}=.66$.

As Table 3 shows, similar relations emerged, with the exception that we found no significant relation between perceived severity and physical distancing in the university sample.

Of all covariates, only the week and day variables were significantly related to physical distancing behavior. The week had a small negative effect on physical distancing behaviors, meaning that physical distancing was lower in the second week compared to the first week of measurement. In the school sample, there was also a small negative effect of the day of the week. This means that, besides an overall decline in adherence to the regulations from week to week, adolescents also decreased in their physical distancing behaviors as a week progressed from Monday to Friday.
The univariate analyses presented in Tables 4 and 5 yielded significant relations for all psychosocial determinants with physical distancing, but the standardized coefficients suggested varying strength. In summary, the univariate analyses provided support for all hypotheses in both samples, although the effect sizes for the perceived susceptibility were relatively small $(b<.10)$. The multivariate analyses provided support for $\mathrm{H} 1 \mathrm{a}$, (perceived severity) $\mathrm{H} 2 \mathrm{~b}$ (perceived response efficacy), $\mathrm{H} 3 \mathrm{a}$ (descriptive social norm), H3b (injunctive social norm) in both samples, and for $\mathrm{H} 1 \mathrm{~b}$ (perceived susceptibility) in the school sample only. As indicated above, $\mathrm{H} 2 \mathrm{a}$ (self-efficacy) could not be tested due to an omission in the questionnaire. In both the multivariate 


\begin{tabular}{|c|c|c|c|c|c|c|c|c|c|}
\hline \multirow[t]{2}{*}{ PREDICTOR } & \multirow[t]{2}{*}{ CRITERION } & \multirow[t]{2}{*}{ B } & \multicolumn{2}{|c|}{$95 \% C I$} & \multirow[t]{2}{*}{ SE } & \multirow[t]{2}{*}{$\beta$} & \multirow[t]{2}{*}{$D F$} & \multirow[t]{2}{*}{$T$} & \multirow[t]{2}{*}{$P$} \\
\hline & & & LL & UL & & & & & \\
\hline Perceived severity & Physical distancing & .13 & .08 & .16 & .02 & .12 & 3076.28 & 6.29 & $<.000$ \\
\hline Perceived susceptibility & Physical distancing & .08 & .04 & .13 & .02 & .09 & 2844.83 & 4.00 & $<.000$ \\
\hline Response efficacy & Physical distancing & .12 & .10 & .18 & .02 & .14 & 2784.65 & 6.67 & $<.000$ \\
\hline Descriptive norm & Physical distancing & .47 & .52 & .58 & .02 & .55 & 1961.95 & 31.23 & $<.000$ \\
\hline Injunctive norm & Physical distancing & .22 & .27 & .35 & .02 & .31 & 2089.63 & 14.08 & $<.000$ \\
\hline Mass media & Physical distancing & .05 & .01 & .07 & .02 & .04 & 3073.08 & 2.29 & .022 \\
\hline Social media & Physical distancing & .01 & -.02 & .04 & .02 & .01 & 2904.60 & .53 & .593 \\
\hline Interpersonal communication & Physical distancing & -.03 & -.05 & .01 & .02 & -.02 & 2952.31 & -1.24 & .213 \\
\hline Mass media & Perceived severity & .02 & -.01 & .04 & .01 & .02 & 3981.30 & 1.30 & .194 \\
\hline Social media & Perceived severity & .03 & .00 & .05 & .01 & .02 & 3804.03 & 1.93 & .054 \\
\hline Interpersonal communication & Perceived severity & -.02 & -.04 & .01 & .02 & -.01 & 3845.66 & -1.27 & .205 \\
\hline Mass media & Perceived susceptibility & -.03 & -.04 & .00 & .01 & -.02 & 3882.69 & -1.83 & .068 \\
\hline Social media & Perceived susceptibility & -.03 & -.04 & .00 & .01 & -.02 & 3737.34 & -1.86 & .064 \\
\hline Interpersonal communication & Perceived susceptibility & .00 & -.02 & .02 & .02 & .00 & 3768.29 & -.15 & .878 \\
\hline Mass media & Response efficacy & -.02 & -.04 & .01 & .02 & -.02 & 3887.26 & -1.29 & .198 \\
\hline Social media & Response efficacy & -.01 & -.02 & .02 & .02 & .00 & 3739.52 & -.49 & .626 \\
\hline Interpersonal communication & Response efficacy & -.02 & -.03 & .01 & .02 & -.01 & 377.80 & -1.11 & .268 \\
\hline Mass media & Descriptive norm & .06 & .00 & .09 & .03 & .05 & 2227.78 & 2.13 & .033 \\
\hline Social media & Descriptive norm & -.03 & -.05 & .02 & .03 & -.02 & 2117.46 & -.88 & .379 \\
\hline Interpersonal communication & Descriptive norm & -.04 & -.06 & .01 & .03 & -.03 & 2146.49 & -1.36 & .175 \\
\hline Mass media & Injunctive norm & .00 & -.03 & .03 & .03 & .00 & 2526.49 & .00 & .997 \\
\hline Social media & Injunctive norm & -.03 & -.04 & .01 & .03 & -.02 & 2389.07 & -1.12 & .261 \\
\hline Interpersonal communication & Injunctive norm & -.06 & -.06 & .00 & .03 & -.03 & 2393.37 & -2.04 & .042 \\
\hline
\end{tabular}

Table 4 Univariate Linear Mixed-Effects Predicting Physical Distancing Behavior in the School Sample.

and the univariate analyses, the perceived descriptive norm prevailed with the largest standardized effect size, being three to four times as strong as the other significant relations.

\section{COMMUNICATION ABOUT COVID-19 AND PHYSICAL DISTANCING BEHAVIOR: DIRECT AND INDIRECT RELATIONS (H4-H5)}

The fourth hypothesis focused on the level of exposure to communication about the COVID-19 pandemic from various types of communication on young people's physical distancing, hypothesizing that higher levels of exposure to COVID-19 information via ( $\mathrm{H} 4 \mathrm{a})$ mass media, (H4b) social media, and (H4C) interpersonal communication would relate to more physical distancing behavior.

As can be seen in Table 6, only the level of communication about the COVID-19 consumed on mass media significantly related to physical distancing in the school sample. As shown in Table 7, none of the three types of communication were related to physical distancing in the university sample. The same patterns emerged for the univariate analyses (Tables 4 and 5). This means that we found almost no evidence that supports hypothesis 4, except for the partial evidence for hypothesis $4 \mathrm{a}$ in the school sample. That is, adolescents who had heard or seen more about COVID-19 on mass media, more often kept a physical distance from others.

The fifth hypothesis investigated whether the relation between exposure to communication about the COVID-19 pandemic from various types of communication and physical distancing behavior would be mediated by (a) perceived severity, (b) perceived susceptibility, (c) perceived efficacy, (d) descriptive norms, and (e) injunctive norms. For each of the hypothesized paths, the total relation was broken down into the direct relation between the communication type and physical distancing behavior, and the indirect relation mediated by one of the behavioral predictors.

Table 8 shows the total, the direct, and the indirect effects in the school sample. As can be seen, an indirect effect of descriptive norms was observed in the relation 


\begin{tabular}{|c|c|c|c|c|c|c|c|c|c|}
\hline \multirow[t]{2}{*}{ PREDICTOR } & \multirow[t]{2}{*}{ CRITERION } & \multirow[t]{2}{*}{$B$} & \multicolumn{2}{|c|}{$95 \% C I$} & \multirow[t]{2}{*}{ SE } & \multirow[t]{2}{*}{$\beta$} & \multirow[t]{2}{*}{$D F$} & \multirow[t]{2}{*}{$T$} & \multirow[t]{2}{*}{$P$} \\
\hline & & & LL & UL & & & & & \\
\hline Perceived severity & Physical distancing & .14 & .08 & .16 & .03 & .12 & 2385.72 & 5.39 & $<.000$ \\
\hline Perceived susceptibility & Physical distancing & .06 & .02 & .11 & .02 & .07 & 2349.69 & 2.98 & .003 \\
\hline Response efficacy & Physical distancing & .24 & .19 & .28 & .02 & .23 & 1975.66 & 9.75 & $<.000$ \\
\hline Descriptive norm & Physical distancing & .43 & .45 & .54 & .02 & .50 & 1391.40 & 22.12 & $<.000$ \\
\hline Injunctive norm & Physical distancing & .21 & .22 & .31 & .02 & .27 & 2253.68 & 12.05 & $<.000$ \\
\hline Mass media & Physical distancing & .02 & -.02 & .06 & .02 & .02 & 2507.38 & 1.13 & .258 \\
\hline Social media & Physical distancing & .02 & -.01 & .05 & .02 & .02 & 2405.63 & 1.14 & .253 \\
\hline Interpersonal communication & Physical distancing & -.03 & -.06 & .01 & .02 & -.02 & 2461.32 & -1.32 & .187 \\
\hline Mass media & Perceived severity & .02 & .00 & .05 & .01 & .02 & 3228.28 & 1.64 & .100 \\
\hline Social media & Perceived severity & .04 & .01 & .06 & .01 & .04 & 3121.86 & 2.97 & .003 \\
\hline Interpersonal communication & Perceived severity & .01 & -.01 & .03 & .01 & .01 & 3174.95 & .83 & .408 \\
\hline Mass media & Perceived susceptibility & .00 & -.02 & .03 & .02 & .00 & 3226.73 & .22 & .827 \\
\hline Social media & Perceived susceptibility & -.02 & -.04 & .01 & .02 & -.02 & 3123.81 & -1.41 & .158 \\
\hline Interpersonal communication & Perceived susceptibility & .04 & .01 & .05 & .02 & .03 & 3176.56 & 2.42 & .016 \\
\hline Mass media & Response efficacy & -.03 & -.05 & .00 & .01 & -.02 & 3171.68 & -1.99 & .046 \\
\hline Social media & Response efficacy & -.03 & -.05 & -.01 & .01 & -.03 & 3089.05 & -2.51 & .012 \\
\hline Interpersonal communication & Response efficacy & -.02 & -.04 & .00 & .01 & -.02 & 3129.56 & -1.75 & .080 \\
\hline Mass media & Descriptive norm & -.04 & -.08 & .01 & .03 & -.03 & 1602.81 & -1.36 & .175 \\
\hline Social media & Descriptive norm & -.04 & -.07 & .01 & .03 & -.03 & 1534.41 & -1.30 & .194 \\
\hline Interpersonal communication & Descriptive norm & -.07 & -.09 & .00 & .03 & -.05 & 1585.68 & -2.09 & .037 \\
\hline Mass media & Injunctive norm & -.03 & -.04 & .01 & .02 & -.02 & 321.60 & -1.42 & .157 \\
\hline Social media & Injunctive norm & -.01 & -.03 & .02 & .02 & -.01 & 3111.61 & -.52 & .602 \\
\hline Interpersonal communication & Injunctive norm & .01 & -.02 & .03 & .02 & .01 & 316.94 & .52 & .601 \\
\hline
\end{tabular}

Table 5 Univariate Linear Mixed-Effects Predicting Physical Distancing Behavior in the University Sample.

\begin{tabular}{|c|c|c|c|c|c|c|c|c|}
\hline \multirow[t]{2}{*}{ VARIABLE } & \multirow[t]{2}{*}{ B } & \multicolumn{2}{|c|}{$95 \%$ CI FOR B } & \multirow[t]{2}{*}{ SE } & \multirow[t]{2}{*}{$\beta$} & \multirow[t]{2}{*}{$D F$} & \multirow[t]{2}{*}{$T$} & \multirow[t]{2}{*}{$P$} \\
\hline & & $L L$ & $U L$ & & & & & \\
\hline Intercept & 4.86 & 4.66 & 5.07 & 0.10 & & 2739.29 & 47.39 & $<.001$ \\
\hline Social media & 0.00 & -0.04 & 0.04 & 0.02 & 0.00 & 2836.55 & 0.02 & 0.985 \\
\hline Mass media & 0.05 & 0.01 & 0.09 & 0.02 & 0.04 & 3041.56 & 2.44 & 0.015 \\
\hline Interpersonal communication & -0.04 & -0.08 & 0.01 & 0.02 & -0.03 & 2905.09 & -1.69 & 0.091 \\
\hline Sex (Male) & -0.07 & -0.25 & 0.12 & 0.09 & -0.03 & 455.50 & -0.72 & 0.470 \\
\hline Age & -0.03 & -0.08 & 0.02 & 0.02 & -0.05 & 450.20 & -1.24 & 0.216 \\
\hline Mean temperature & -0.01 & -0.02 & 0.00 & 0.00 & -0.03 & 2749.07 & -2.24 & 0.025 \\
\hline Week & -0.12 & -0.18 & -0.06 & 0.03 & -0.05 & 2741.65 & -3.91 & $<.001$ \\
\hline Day & -0.03 & -0.05 & -0.01 & 0.01 & -0.04 & 2718.36 & -2.95 & 0.003 \\
\hline
\end{tabular}

Table 6 Multivariate Linear Mixed-Effects Model Predicting Physical Distancing Behavior in the School Sample.

Note: $N=460$. $\mathrm{ICC}_{\text {Participant }}=.61$. Marginal $\mathrm{R}^{2}=.01$. Conditional $\mathrm{R}^{2}=.62$. 


\begin{tabular}{|c|c|c|c|c|c|c|c|c|}
\hline \multirow[t]{2}{*}{ VARIABLE } & \multirow[t]{2}{*}{ B } & \multicolumn{2}{|c|}{$95 \%$ CI FOR B } & \multirow[t]{2}{*}{ SE } & \multirow[t]{2}{*}{$\beta$} & \multirow[t]{2}{*}{$D F$} & \multirow[t]{2}{*}{$T$} & \multirow[t]{2}{*}{$P$} \\
\hline & & $L L$ & $U L$ & & & & & \\
\hline Intercept & 4.95 & 4.68 & 5.21 & 0.14 & - & 1960.33 & 36.52 & $<.001$ \\
\hline Social media & 0.02 & -0.02 & 0.07 & 0.02 & 0.02 & 2364.65 & 1.01 & 0.314 \\
\hline Mass media & 0.03 & -0.02 & 0.07 & 0.02 & 0.02 & 2478.81 & 1.10 & 0.273 \\
\hline Interpersonal communication & -0.04 & -0.09 & 0.00 & 0.02 & -0.03 & 2420.56 & -1.84 & 0.065 \\
\hline Sex (Male) & -0.09 & -0.32 & 0.14 & 0.12 & -0.03 & 377.99 & -0.76 & 0.450 \\
\hline Age & -0.02 & -0.06 & 0.03 & 0.02 & -0.03 & 384.96 & -0.71 & 0.475 \\
\hline Mean temperature & -0.02 & -0.04 & -0.01 & 0.01 & -0.06 & 2246.58 & -4.10 & $<.001$ \\
\hline Week & -0.09 & -0.15 & -0.02 & 0.03 & -0.04 & 2245.18 & -2.72 & 0.007 \\
\hline Day & 0.03 & 0.01 & 0.06 & 0.01 & 0.04 & 2224.17 & 3.06 & 0.002 \\
\hline
\end{tabular}

Table 7 Multivariate Linear Mixed-Effects Model Predicting Physical Distancing Behavior in the University Sample. Note: $N=380$. $\mathrm{ICC}_{\text {participant }}=.59$. Marginal $\mathrm{R}^{2}=.01$. Conditional $\mathrm{R}^{2}=.59$.

\begin{tabular}{|c|c|c|c|c|c|c|c|}
\hline & \multirow{2}{*}{$\begin{array}{l}\text { TOTAL } \\
\text { EFFECT }\end{array}$} & \multirow{2}{*}{$\begin{array}{l}\text { DIRECT } \\
\text { EFFECT }\end{array}$} & \multicolumn{5}{|c|}{ INDIRECT EFFECT VIA } \\
\hline & & & $\begin{array}{l}\text { PERCEIVED } \\
\text { SEVERITY }\end{array}$ & $\begin{array}{l}\text { PERCEIVED } \\
\text { SUSCEPTIBILITY }\end{array}$ & $\begin{array}{l}\text { RESPONSE } \\
\text { EFFICACY }\end{array}$ & $\begin{array}{l}\text { DESCRIPTIVE } \\
\text { NORM }\end{array}$ & $\begin{array}{l}\text { INJUNCTIVE } \\
\text { NORM }\end{array}$ \\
\hline Mass media & $.096^{*}$ & $.057^{*}$ & .001 & -.001 & -.002 & $.039^{*}$ & .002 \\
\hline Social media & $.058^{*}$ & $.069 *$ & $.002^{*}$ & -.001 & $<.001$ & -.012 & -.001 \\
\hline $\begin{array}{l}\text { Interpersonal } \\
\text { communication }\end{array}$ & -.013 & .016 & -.002 & $<.001$ & -.001 & -.022 & -.004 \\
\hline
\end{tabular}

Table 8 Total Effects, Direct Effects and Indirect Effects on Physical Distancing Behavior in the School Sample.

Note: $N=481$.

* 95\% Confidence Interval does not include 0.

between mass media communication about COVID-19 and physical distancing behavior, $b=.039, b_{\text {bootstrapped }}=$ $.041,95 \% \mathrm{CI}=[.013, .069]$. Because we also observed a significant total effect $\left(b_{\text {bootstrapped }}=.102,95 \% \mathrm{CI}=[.051\right.$, $.152])$ and direct effect $\left(b_{\text {bootstrapped }}=.060,95 \% \mathrm{CI}=[.018\right.$, .102]), we conclude that the perceived descriptive norm partially mediated the relation between mass media communication about COVID-19 and physical distancing behavior in the school sample.

Also, an indirect effect of perceived severity was observed in the relation between social media communication about COVID-19 and physical distancing behavior, $b=.002, b_{\text {bootstrapped }}=.002,95 \% \mathrm{CI}=[<.001$, $.005]$. Again, a significant total effect $\left(b_{\text {bootstrapped }}=.063\right.$, $95 \% \mathrm{CI}=[.009, .117])$ and direct effect $\left(b_{\text {bootstrapped }}=.073\right.$, $95 \%$ CI $=[.025, .122])$ was observed. However, in the previous models, we have seen no indication of a relation between mass media communication about COVID-19 and physical distancing behavior, and potentially the direct and total effects are now observed because the control variables could not be included in the mediation models. Therefore, we are cautious in concluding that perceived severity partially mediated the relation between social media communication about COVID-19 and physical distancing behavior in the school sample.
Table 9 shows the total, the direct, and the indirect effects in the university sample. As can be seen, a negative indirect effect of descriptive norms was observed in the relation between interpersonal communication about COVID-19 and physical distancing behavior, $b=-.030$, $b_{\text {bootstrapped }}=-.030,95 \% \mathrm{CI}=[-.058,-.002]$. And because the direct effect was not statistically significant, we conclude that the perceived descriptive norm fully mediated the relation between interpersonal communication about COVID-19 and physical distancing behavior in the university sample.

\section{COMMUNICATION ABOUT COVID-19 AND PHYSICAL DISTANCING BEHAVIOR: THE ROLE OF AFFECTIVE RESPONSES AND PRESS CONFERENCES (RQ1-RQ2)}

With regard to the role of the valence of the affective response to COVID-19 communication (RQ1), two models were used in which the (standardized) types of communication interacted with the (standardized) valence of the three types of communication. In the school sample, none of the interaction parameters related to physical distancing behavior.

However, in the university sample, the interaction between mass media and mass media valence did 
have a small significant relation with physical distancing behavior, $B=.04,95 \% \mathrm{CI}=[.004, .08]$, SE $=.02, d f=$ 2389.47, $p=.028$. Inspecting the simple slopes for negative $(<3)$, neutral $(3-5)$, and positive valence $(>5)$ showed that the relation between physical distancing and mass media was different for those who experienced the valence of communication on mass media as negative (small negative non-significant trend) compared to those who experienced the valence of communication on mass media as neutral to positive (non-significant relation), see Figure 1.

Our second research question explored the relation between COVID-19 national press conferences and young people's physical distancing behavior. In both samples, the average physical distancing was not higher on the day of the press conferences, nor on the day after the press conference as compared to the other days, see Figure 2. In the figure, the days on which a national press conference was released are marked with a vertical line and square boxes.

Second, we looked at the linear relation between the number of days since the last national press conferences and physical distancing behaviors. In both samples, we did not observe a linear relation between the number of days since the last press conference and physical distancing behavior, see Figure 3.

\section{ADDITIONAL ANALYSIS: EXPLORING THE DIRECTIONALITY OF THE RELATION BETWEEN DESCRIPTIVE NORMS AND PHYSICAL DISTANCING BEHAVIOR}

Finally, given the consistently large effect size observed for the relation between descriptive norm and physical distancing behavior, we decided to further investigate the directionality of this relation. Although based on the theory we assume that the direction points from descriptive norm to behavior, it is also conceivable that an individual's engagement in a behavior affects how they perceive peers in their social environment to behave. To test both effects simultaneously we used random intercept cross-lagged models the causal relations between the descriptive norm and physical distancing behavior on consecutive days and controlling for the observed association (covariance)

\begin{tabular}{|c|c|c|c|c|c|c|c|}
\hline & \multirow{2}{*}{$\begin{array}{l}\text { TOTAL } \\
\text { EFFECT }\end{array}$} & \multirow{2}{*}{$\begin{array}{l}\text { DIRECT } \\
\text { EFFECT }\end{array}$} & \multicolumn{5}{|c|}{ INDIRECT EFFECT VIA } \\
\hline & & & $\begin{array}{l}\text { PERCEIVED } \\
\text { SEVERITY }\end{array}$ & $\begin{array}{l}\text { PERCEIVED } \\
\text { SUSCEPTIBILITY }\end{array}$ & $\begin{array}{l}\text { RESPONSE } \\
\text { EFFICACY }\end{array}$ & $\begin{array}{l}\text { DESCRIPTIVE } \\
\text { NORM }\end{array}$ & $\begin{array}{l}\text { INJUNCTIVE } \\
\text { NORM }\end{array}$ \\
\hline Mass media & -.001 & .008 & .001 & .000 & -.002 & -.006 & -.001 \\
\hline Social media & .025 & .039 & .002 & -.001 & -.004 & -.011 & -.001 \\
\hline $\begin{array}{l}\text { Interpersonal } \\
\text { communication }\end{array}$ & $-.072^{*}$ & -.041 & .000 & .001 & -.002 & $-.030^{*}$ & .001 \\
\hline
\end{tabular}

Table 9 Total Effects, Direct Effects and Indirect Effects on Physical Distancing Behavior in the University Sample.

Note: $N=404$.

* 95\% Confidence Interval does not include 0.

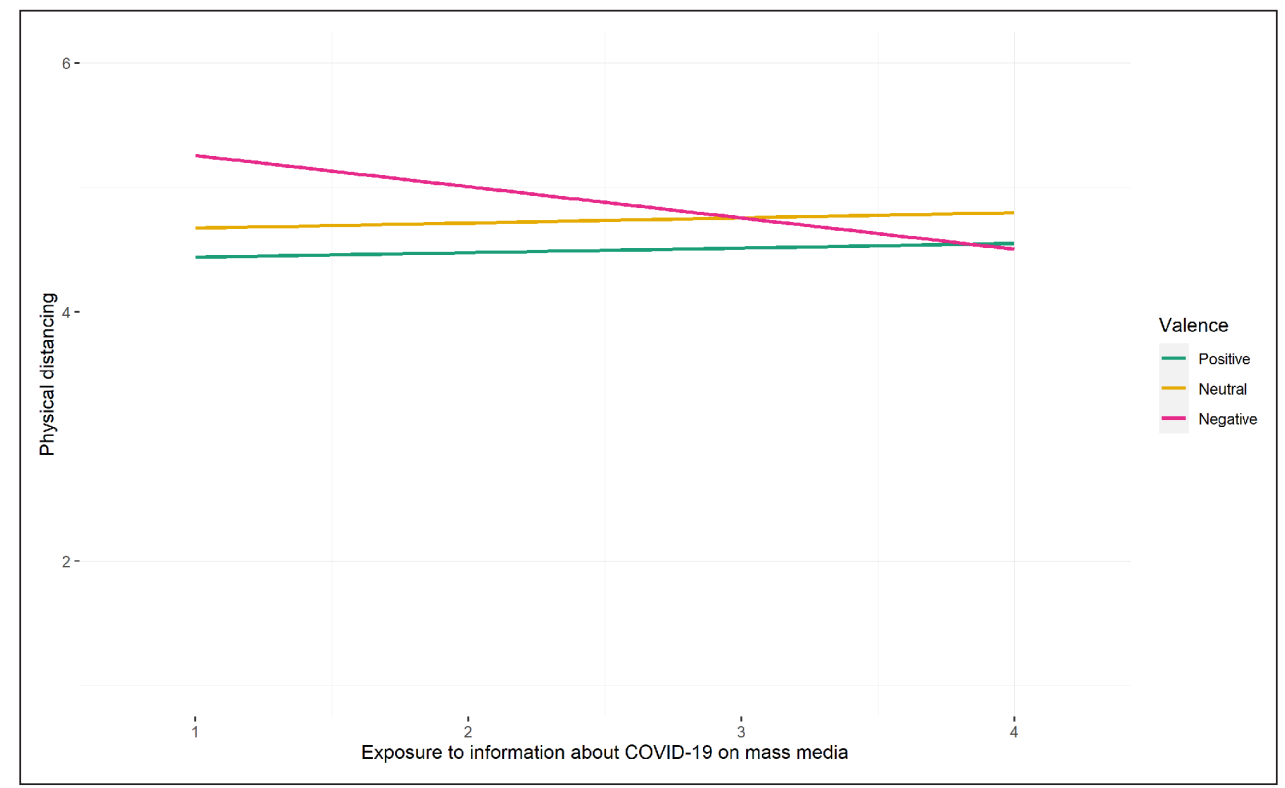

Figure 1 Simple Slopes of the Interaction Between Mass Media and Mass Media Valence on Physical Distancing in the University Sample. 


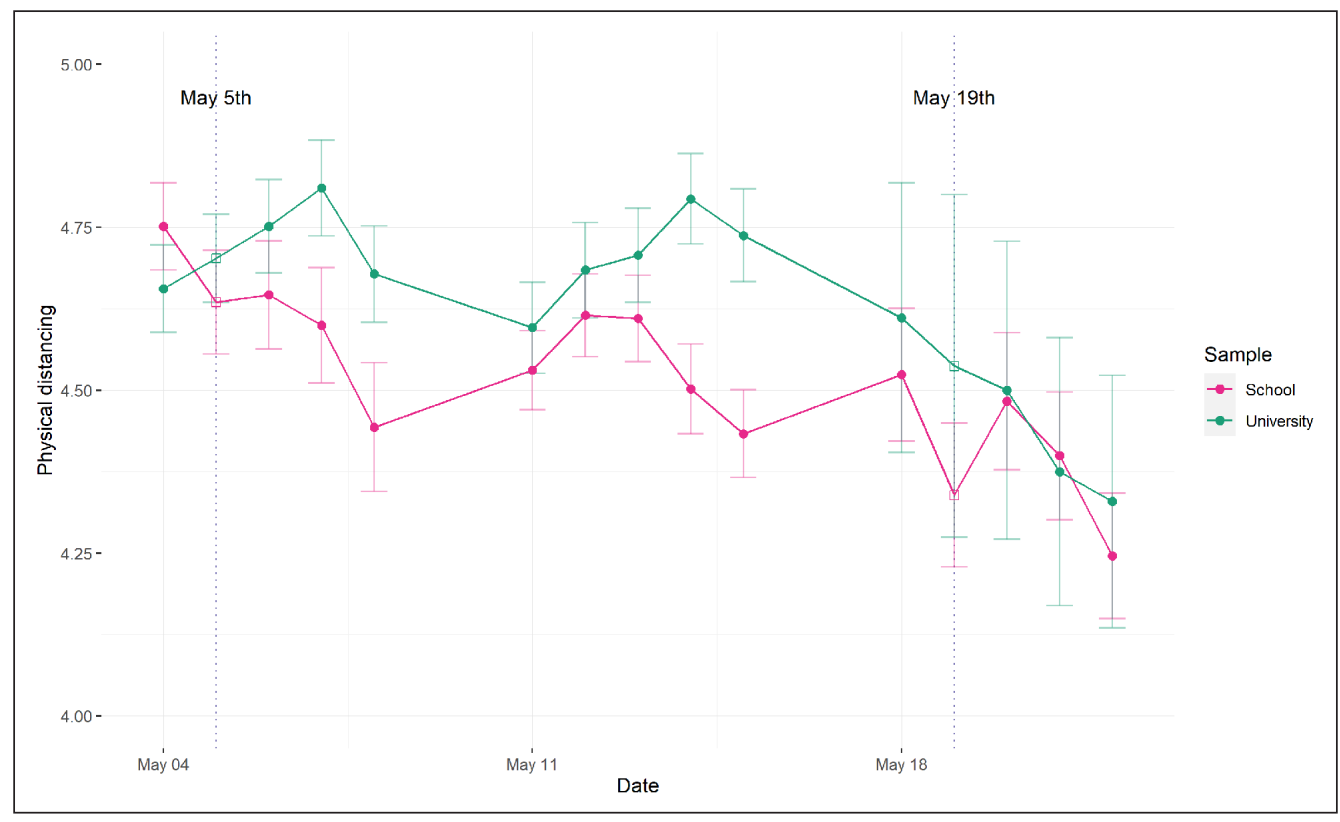

Figure 2 Average Physical Distancing Behavior in the Two Samples from Monday May 4th until Friday May 22nd. Note: Days on which a press conference was held are marked with a box and a vertical line (May 5th and May 19th).

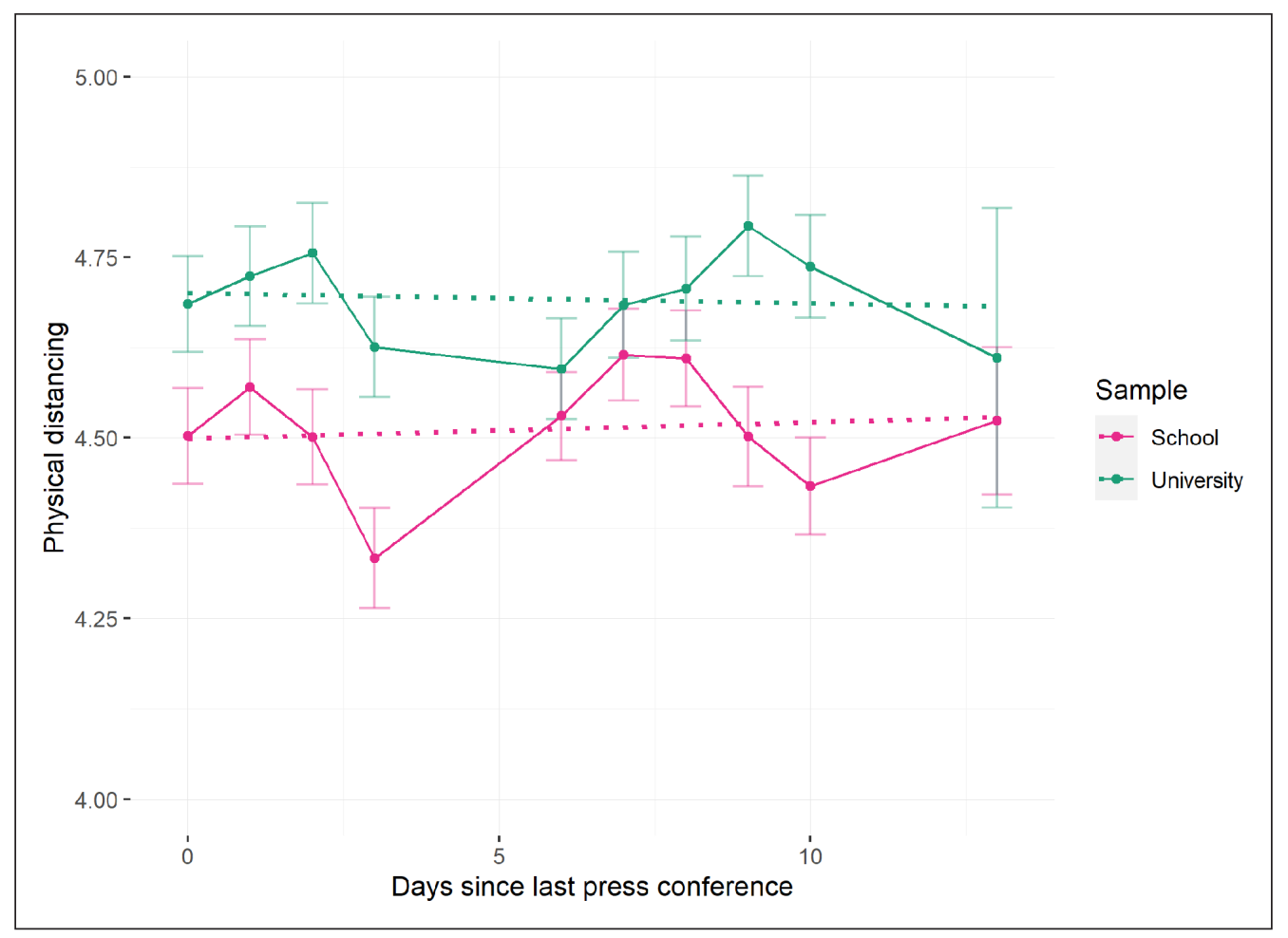

Figure 3 Average Physical Distancing Behavior in the Two Samples in the Days After a National Press Conference.

Note: The dotted line represents the estimated linear relation between the mean physical distancing behavior and the days since the last press conference.

between descriptive norm and physical distancing and their autoregressive effects (Hamaker et al., 2015). For each sample, a separate model was specified in which the lagged regressions predicted the behavior or the descriptive norms on the subsequent day of the week. The week (week 1 vs week 2 ) was added as a grouping variable to control for differences between the weeks. We constrained all covariances, autoregressive effects, and cross-lagged effects to be the same to have average effects for the school sample and the university sample.

The models had a good fit (Hu \& Bentler, 1999; Kline, 2015) for the school sample; $\chi^{2} / \mathrm{df}=1.528$, CFI $=.980$, $\mathrm{TLI}=.980$, RMSEA $=.034$, SRMR $=.052$, and the university sample; $\chi^{2} / \mathrm{df}=1.416$, CFI $=.979, \mathrm{TLI}=.980$, RMSEA $=.032$, $\mathrm{SRMR}=.056$. Also, significant average covariances of the descriptive norm and physical distancing behavior on the same day were observed in both the school sample $(b$ $=.335, S E=.022, z=15.23, p<.001)$ and the university 
sample $(b=.241, S E=.020, z=11.98, p<.001)$. As can be seen in Tables 10 and 11, the autoregressive effect of the descriptive norm was found in the school sample and the autoregressive effects of physical distancing behaviors were observed in both samples. With regard to the directionality of the relation, only a significant effect of physical distancing on the descriptive norm in the subsequent day was observed in the university sample, indicating a reversed direction leading from physical distancing behavior to the perceived social norms. All other relations were nonsignificant, yielding no further insight into the directionality of the relation between perceived social norms and physical distancing behavior.

\section{DISCUSSION}

The aim of this study was to gain a better understanding of young people's physical distancing behavior during the COVID-19 pandemic. We specifically focused on investigating the psychosocial determinants of young people's physical distancing behavior, and the role of exposure to information about COVID-19 through direct (i.e., interpersonal) and mediated communication (i.e., mass media, social media). The aim was addressed in a daily diary study among Dutch adolescents (school sample) and young adults (university sample), involving daily surveys administered on weekdays during two weeks in May 2020, a few months after the start of the COVID-19 pandemic. Based on our findings, four main conclusions can be drawn.

First, our findings demonstrate that the perceived descriptive norm was the strongest predictor of physical distancing behavior among both adolescents and young adults, followed by the perceived response efficacy, and the injunctive norm. The perceived severity was only a significant predictor of physical distancing in the school sample. It should be noted that the average score for this measure was very high, which may indicate a ceiling effect (most adolescents experienced the spread of the COVID-19 virus as highly severe). Nevertheless, there was still enough variance in the variable to signal an effect, and robust estimation yielded similar results. The descriptive norm was even more strongly prevailing among adolescents, while the perceived response efficacy appeared to play a complementary important role among young adults. These results indicate that the descriptive norm seems, relatively, the most important psychosocial determinant to target in physical distancing interventions in young people. Interestingly, our multivariate analyses did not yield any evidence for perceived susceptibility as a predictor of physical distancing behavior, neither among adolescents nor young adults, while the univariate analyses showed only a weak association. Potentially, some of the individual behavioral determinants become redundant in predicting physical activity when all other predictors are considered, due to interrelatedness, or dependence, of these psychosocial constructs. Also, perceived susceptibility could overlap with other predictors, resulting in a non-significant unique explained variance that is not overlapping with any of the other predictors (G.-J. Peters $\&$ Crutzen, 2018).

These findings are largely in line with psychosocial models, such as the Health Belief Model (Glanz et al., 2015) and the Protection Motivation Theory (Rogers, 1975;

\begin{tabular}{|c|c|c|c|c|c|c|c|}
\hline \multirow[t]{2}{*}{ PREDICTOR } & \multirow[t]{2}{*}{ CRITERION (T+1) } & \multirow[t]{2}{*}{ B } & \multicolumn{2}{|c|}{$95 \%$ CI FOR B } & \multirow[t]{2}{*}{$S E$} & \multirow[t]{2}{*}{$z$} & \multirow[t]{2}{*}{$P$} \\
\hline & & & $L L$ & $U L$ & & & \\
\hline Descriptive norm & Descriptive norm & .10 & .01 & .19 & .05 & 2.22 & .026 \\
\hline Physical distancing & Descriptive norm & .03 & -.07 & .13 & .05 & 0.62 & .538 \\
\hline Descriptive norm & Physical distancing & .05 & -.01 & .11 & .03 & 1.50 & .134 \\
\hline Physical distancing & Physical distancing & .09 & .01 & .17 & .04 & 2.18 & .029 \\
\hline
\end{tabular}

Table 10 Random Intercept Cross-lagged Panel Model for the School Sample. Note: $N=464$.

\begin{tabular}{lllllllll}
\hline PREDICTOR' & CRITERION (T+1) & B & \multicolumn{2}{c}{$95 \%$ CI FOR B } & SE & Z & P \\
& & & \multicolumn{2}{c}{ LL } & UL & & & \\
\hline Descriptive norm & Descriptive norm & 0.02 & -0.06 & 0.11 & 0.04 & 0.51 & 0.613 \\
\hline Physical distancing & Descriptive norms & 0.10 & 0.00 & 0.19 & 0.05 & 1.96 & 0.050 \\
\hline Descriptive norm & Physical distancing & -0.03 & -0.10 & 0.04 & 0.03 & -0.92 & 0.360 \\
\hline Physical distancing & Physical distancing & 0.21 & 0.12 & 0.29 & 0.04 & 4.84 & 0.000 \\
\hline
\end{tabular}

Table 11 Random Intercept Cross-lagged Panel Model for the University Sample.

Note: $N=398$ 
Witte, 1992), showing that perceptions about the threat and perceptions about the efficacy of the recommended preventive behavior both related to physical distancing behavior. Additionally, in line with Social Cognitive Theory (Bandura, 1986, 2004), our findings show that perceived social norms are related to young people's physical distancing behavior as well. This confirms the argument previously made by others that when studying physical distancing behavior or other preventive health behaviors, social norms must be considered to gain a full understanding of the behavior (Bavel et al., 2020; Chan et al., 2020). Importantly, conclusions with regard to the relation between perceived social norms and physical distancing behavior should be interpreted with caution. Based on Social Cognitive Theory (Bandura, 1986, 2004) a plausible interpretation of this relation would be that young people's physical distancing behavior is influenced by how they perceive peers in their social environment behave. However, the observed relation could also be interpreted as a false consensus effect (Ross et al., 1977), whereby individuals exaggerate the likelihood that other people are like themselves. In other words, the young people in our sample could have assumed that their physical distancing behavior is relatively widespread among their friends. As such, their reflection on their own physical distancing behavior may have affected their perceptions of the behavior of their friends (i.e, perceived social norms). Although our additional analyses into the directionality of the relation between social norms and physical distancing give some indication that physical distancing influences the perceived social norm, we cannot tell based on our data whether this is caused by a false consensus effect.

Taken together, the above described findings suggest that for behavioral intervention (research), social norms, perceived severity, and perceived efficacy of the behavioral measures appear to be the most promising determinants to focus on. Despite the convincing and consistent importance of social norms in our analyses, we recommend intervention research to also investigate the potential of alternative determinants, because social norms may be more difficult to manipulate than perceived severity and response efficacy.

A second conclusion that we can draw based on our findings is that adolescents who are more exposed to communication about the COVID-19 pandemic on mass media also engage more in physical distancing behavior, which is explained by an increased perception of the behavior in their social environment. Adolescents who were more often exposed to communication about COVID-19 on mass media perceived that their friends more often kept a 1.5-meter distance from others, which in turn related to an increase in their own physical distancing behavior. This indicates that social norms can be derived through indirect mediated communication, for example through mass media (Hong \& Kim, 2020;
Rimal \& Storey, 2020). It should be noted that we have not found any statistical evidence for this relation among young adults. Moreover, the above described results need to be interpreted with caution, because the observed relation for mass media is small and our study does not allow conclusions about the directionality for this mediated association.

Aside from a few weak indirect paths between the three types of communication and physical distancing, hardly any evidence was found that exposure to COVIDrelated information was related to physical distancing behavior. One explanation for this is that the COVID-19 related communication on mass media, overall, is more formal and controlled than information via social media and interpersonal communication. During the COVID-19 pandemic, mass media communication channels such as television, radio, newspaper, news apps, and websites are being used extensively by the government, health organizations, and journalists to share information about COVID-19 and specifically about physical distancing as one of the recommended behaviors to combat the virus. Information about COVID-19 and physical distancing on social media and between is also shared by informal sources (e.g., influencers, celebrities, friends, and other acquaintances) (Manganello et al., 2020), while interpersonal communication only involves informal sources. Our findings warrant further research to dive deeper into the specific content of the COVID-19 communication that individuals are exposed to, for example differentiating between more or less controlled and reliable content.

Providing further support for that recommendation, our exploratory analyses regarding affective responses to communication demonstrated that young adults' exposure to COVID-related mass media communication was negatively associated with physical distancing for those young adults who experienced more negative feelings with the exposure. This indicates that the valence of the feelings people experience about information about COVID-19 can influence the direction of the relation between exposure to communication about COVID-19 and physical distancing behavior.

This is in line with the affect-as-information hypothesis (Storbeck \& Clore, 2008) and earlier research showing that more negative valenced experiences can deter people from performing the desired behavior, while more positively valenced experiences can actually stimulate people to perform the behavior (Janicke-Bowles et al., 2019; Witte, 1992). Confirmatory replications of these findings are needed to draw more robust conclusions, but these preliminary results suggest that the valence of the feelings people experience about information about COVID-19 should be taken into account when studying the impact of pandemic-related communication. Referring to our recommendation to dive deeper into the specific content of communication, affective 
responses are highly likely to relate to the valence of the communication, for example distinguishing between more or less threatening, hopeful and/or inspiring content.

Fourth, in both the school and university samples, we did not observe an increase in physical distancing behavior on the day of the national press conferences nor on the days thereafter. However, in general, we did see a small decline in physical distancing behavior over time (within the weeks but also between the weeks). An explanation for this might be that in the period in which this research was conducted, the number of COVIDrelated infections, hospital admissions, and deaths in the Netherlands decreased and a 'road map' containing the gradual phasing out of the strict lockdown measures (e.g., reopening primary schools, contact professions back to work, outdoor sports allowed, reopening restaurants and bars) was presented by the government. Although the advice to keep a distance from others remained unabated despite these relaxations, it is quite possible that the participants in this study felt less compelled to adhere to it because of these positive developments.

Finally, our analyses yielded another opening for further investigation, namely that the weather conditions, particularly the daily temperature, played a significant role in young people's physical distancing behavior. Some of our analyses, in which the daily temperature was added as a covariate, showed that the higher the daily temperature, the less likely young people were to keep a distance. An explanation for this is that when the temperature rises, people go outside more often and meet with others, for example in a park, forest, or on the beach. This finding shows that contextual factors, such as the weather, can play an important role in young people's compliance with the behavioral regulations. This insight might be of interest to other researchers as well as professionals involved in COVID-19 policy development, which may not only involve behavioral intervention, stimulating ability and motivation to engage in the desired behavior, but also intervention in the physical environment, increasing the opportunity to engage in the behavior (Michie et al., 2011).

\section{STRENGTHS, LIMITATIONS, AND RECOMMENDATIONS}

By using a daily diary methodology to measure physical distancing behavior, its behavioral determinants, and exposure to communication about COVID-19, we were able to address some of the shortcomings of retrospective self-reported measures. More specifically, with the used methodology we were able to assess the variety of variables more accurately while addressing certain confounders that have to do with the timing of the measurement (for example, answering the questionnaire on Monday versus a Friday) or factors that differ between days (such as the weather or national press conferences).
Furthermore, this study has pursued transparent, openscience practices in which the hypotheses and analyses have been preregistered and the data and scripts are publicly available.

The research also has some limitations that must be considered when interpreting the findings and that can be addressed in future research. First, although we intended to measure perceived self-efficacy as one of the behavioral determinants, unfortunately, this variable was not included in the daily questionnaires due to a technical error. According to health behavior theory and research (Glanz et al., 2015; Witte, 1992), people who believe in their capability to engage in protective behavior (i.e., high self-efficacy) are more likely to engage in the behavior than those with low self-efficacy (Rosenstock et al., 2016). In order to fully understand what drives young people's physical distancing behavior, future research should investigate the importance of self-efficacy (i.e., young people's belief in their own ability to keep a physical distance of 1.5 meter from others) as one of the behavioral determinants of young people's physical distancing behavior.

Second, physical distancing was measured through self-report. The respondents were asked to report each day how often they had kept a physical distance from others in the past 24 hours. It is conceivable that the actual physical distancing behavior of the participants deviated from what they reported, partly because selfreporting of behavior is subject to recall bias. Even though the measures used were adequate to assess fluctuations and associations with the determinants, future research could try to investigate the physical distancing behavior of young people more objectively, for example by using smartphone Bluetooth technology with which proximity to others can be automatically recorded (Simoski et al., 2020; Woudenberg et al., 2020). Or perhaps, with additional consent, using data from corona exposure apps.

Third, a comparable limitation applies to the measurement of exposure to information about COVID-19, which indicated young people's subjective assessment of the amount of information they were exposed to. The actual, objective amount of information exposure can deviate from this subjective assessment. Also, as indicated above, because information exposure was measured at a general level we do not know to what specific COVID-19 related content they were exposed. For future research, it is important to investigate in a more objective way how much of what kind of information young people consume and how that is, subsequently, related to their physical distancing behavior, for example by using media use tracking tools combined with content analysis.

Fourth, in this study, students could voluntarily register for participation. A disadvantage of this method is that self-selection bias can occur, which in this study may have caused a gender imbalance (more young women 
than young men) in the sample. Based on the data, we cannot conclude that there are differences in the physical distancing behavior of young men and women, although other studies have found lower compliance among young males. A possible explanation is that the young males who agreed to participate were those inclined to be more conscientious or public-spirited and as a result also more inclined to adhere to the COVID-preventive measures, such as physical distancing. Consequently, they may not be representative of the broader young male population.

Finally, it should be noted that based on our data and analyses, no conclusions can be drawn about the directionality or the causality of the relations found. Our preliminary analyses exploring the directionality of the relation between the descriptive social norm and physical distancing behavior did not yield unambiguous additional insights. It is conceivable that these relations take more time to grow, or merely co-occur after the first steep increase in the early days of the crisis. It should be noted that most of our participants engaged in physical distancing behaviors, and fluctuations might pertain to slight dents in the maintenance of the behavior (for example due to temporary decreased ability or motivation). Further longitudinal research is needed to establish the causality of the relations found, varying between different intervals of time used in the analytical models. Furthermore, experimental research is needed to come to decisive conclusions about the causality of the relations observed, and their value for public intervention policies. Rapid-cycle experiments might be the most promising next step to select a strategy for larger-scale field interventions, testing and comparing the efficacy of targeting the various behavioral determinants. The rapid-cycle evaluation approach (Cody \& Asher, 2014) involves small-scale studies that use random assignment to determine the impact of (components of) an intervention program over a short time-span and, thereby, allow to test and compare various intervention strategies to develop and improve intervention programs.

Our study indicates that such interventions should focus on descriptive and injunctive norms, and/or the perceived severity and the perceived efficacy of the behavioral measure. Social network intervention might provide a promising avenue (Smit et al., 2020; Valente, 2012; Van Woudenberg et al., 2020), in which selected peer influencers (or even social media influencers) can be encouraged to explain and endorse the publicly communicated behavioral measures, emphasizing the severity of the spreading of the virus and the efficacy of the behavior in stopping the virus from spreading. Such influencers might even encourage the use of reliable public information, for example following official sources such as governmental sources and the national health institute. Based on the literature on communication to young people (Buijzen, in press; Smit et al., in press; Yeager et al., 2018), it is crucial that such interventions are developed in collaboration with the target group and the influencers, and that the information provided is clear and simple, preferably focusing on one target behavior.

\section{DATA ACCESSIBILITY STATEMENT}

The data, syntax and output files are all stored on the Open Science Framework (OSF, https://osf.io/3qgud/).

\section{ETHICS AND CONSENT}

Informed consent was obtained from the participants before the start of the first measurement. For participants younger than 16, informed consent was obtained from one of the parents. Study procedures were approved by the Ethics Committee of the Erasmus University Rotterdam on April 16 th 2020 (application number 20-036).

\section{FUNDING INFORMATION}

The research leading to these results has received funding from the NWO Vici grant, file number VI.C.181.045, and the Spinoza prize awarded to Prof. dr. Eveline Crone.

\section{COMPETING INTERESTS}

The authors have no competing interest to disclose.

\section{AUTHOR AFFILIATIONS}

Esther Rozendaal (D) orcid.org/0000-0003-1234-8496 Erasmus University Rotterdam, NL

Thabo van Woudenberg (D) orcid.org/0000-0002-8586-5876 Erasmus University Rotterdam, NL

Eveline Crone (D) orcid.org/0000-0002-7508-6078

Erasmus University Rotterdam, NL

Kayla Green (D) orcid.org/0000-0001-6962-4047

Erasmus University Rotterdam, NL

Suzanne van de Groep (D) orcid.org/0000-0001-6135-0053 Erasmus University Rotterdam, NL

\section{Rebecca de Leeuw}

Radboud University, NL

Sophie Sweijen (D) orcid.org/0000-0002-9960-0182

Erasmus University Rotterdam, NL

Moniek Buijzen (D) orcid.org/0000-0003-3780-0856

Erasmus University Rotterdam, NL 


\section{REFERENCES}

Anderson, R. M., Heesterbeek, H., Klinkenberg, D., \& Hollingsworth, T. D. (2020). How will country-based mitigation measures influence the course of the COVID-19 epidemic? The Lancet, 395(10228), 931-934. DOI: https:// doi.org/10.1016/50140-6736(20)30567-5

Bandura, A. (1986). Social foundations of thought and action: A social cognitive theory. Prentice-Hall, Inc.

Bandura, A. (2004). Health promotion by social cognitive means. Health Education \& Behavior: The Official Publication of the Society for Public Health Education, 31(2), 143-164. DOI: https://doi.org/10.1177/1090198104263660

Bates, D., Mächler, M., Bolker, B., \& Walker, S. (2014). Fitting Linear Mixed-Effects Models using Ime4. ArXiv:1406.5823 [Stat]. http://arxiv.org/abs/1406.5823. DOI: https://doi. org/10.18637/jss.v067.i01

Bavel, J. J. V., Baicker, K., Boggio, P. S., Capraro, V., Cichocka, A., Cikara, M., Crockett, M. J., Crum, A. J., Douglas, K. M., Druckman, J. N., Drury, J., Dube, O., Ellemers, N., Finkel, E. J., Fowler, J. H., Gelfand, M., Han, S., Haslam, S. A., Jetten, J., ... Willer, R. (2020). Using social and behavioural science to support COVID-19 pandemic response. Nature Human Behaviour, 4(5), 460-471. DOI: https://doi.org/10.1038/ s41562-020-0884-Z

Bish, A., \& Michie, S. (2010). Demographic and attitudinal determinants of protective behaviours during a pandemic: A review. British Journal of Health Psychology, 15(4), 797824. DOI: https://doi.org/10.1348/135910710X485826

Bolsen, T., Leeper, T. J., \& Shapiro, M. A. (2014). Doing What Others Do: Norms, Science, and Collective Action on Global Warming. American Politics Research, 42(1), 65-89. DOI: https://doi.org/10.1177/1532673X13484173

Buijzen, M. (in press). Behind the policy frontlines in the Netherlands during the corona crisis. Journal of Children and Media. DOI: https://doi.org/10.1080/17482798.2020.1 858899

Chan, D. K. C., Zhang, C.-Q., \& Weman-Josefsson, K. (2020). Why people failed to adhere to COVID-19 preventive behaviors? Perspectives from an integrated behavior change model. Infection Control \& Hospital Epidemiology, 1-2. DOI: https://doi.org/10.1017/ice.2020.245

Chu, D. K., Akl, E. A., Duda, S., Solo, K., Yaacoub, S., Schünemann, H. J., Chu, D. K., Akl, E. A., El-harakeh, A., Bognanni, A., Lotfi, T., Loeb, M., Hajizadeh, A., Bak, A., Izcovich, A., Cuello-Garcia, C. A., Chen, C., Harris, D. J., Borowiack, E., ... Schünemann, H. J. (2020). Physical distancing, face masks, and eye protection to prevent person-to-person transmission of SARS-CoV-2 and COVID19: A systematic review and meta-analysis. The Lancet, 395(10242), 1973-1987. DOI: https://doi.org/10.1016/ S0140-6736(20)31142-9

Cialdini, R. B., \& Goldstein, N. J. (2004). Social Influence: Compliance and Conformity. Annual Review of Psychology, 55(1), 591-621. DOI: https://doi.org/10.1146/annurev. psych.55.090902.142015
Cody, S., \& Asher, A. (2014). Smarter, Better, Faster: The Potential for Predictive Analytics and Rapid-Cycle Evaluation to Improve Program Development and Outcomes (98089696543d416996316bdeb6ce50a5; Mathematica Policy Research Reports). Mathematica Policy Research. https://ideas.repec.org/p/mpr/ mprres/98089696543d416996316bdeb6ce50a5.html

Coyne, S. M., Padilla-Walker, L. M., Holmgren, H. G., Davis, E. J., Collier, K. M., Memmott-Elison, M. K., \& Hawkins, A. J. (2018). A meta-analysis of prosocial media on prosocial behavior, aggression, and empathic concern: A multidimensional approach. Developmental Psychology, 54(2), 331-347. DOI: https://doi.org/10.1037/dev0000412

Crutzen, R., \& Peters, G.-J. Y. (2020). Chapter 6 selecting determinants. In The book of behavior change. https://a-bc. gitlab.io/bbc/book-of-behavior-change.pdf

Donadiki, E. M., Jiménez-García, R., Hernández-Barrera, V., Sourtzi, P., Carrasco-Garrido, P., López de Andrés, A., Jimenez-Trujillo, I., \& Velonakis, E. G. (2014). Health Belief Model applied to non-compliance with HPV vaccine among female university students. Public Health, 128(3), 268-273. DOI: https://doi.org/10.1016/j.puhe.2013.12.004

Frey, B. S., \& Meier, S. (2004). Social Comparisons and ProSocial Behavior: Testing "Conditional Cooperation" in a Field Experiment. The American Economic Review, 94(5), 1717 1722. DOI: https://doi.org/10.1257/0002828043052187

Glanz, K., Rimer, B. K., \& Viswanath, K. (2015). Health Behavior: Theory, Research, and Practice. John Wiley \& Sons.

Goldberg, M., Gustafson, A., Maibach, E., van der Linden, S., Ballew, M., Bergquist, P., Kotcher, J., Marlon, J., Rosenthal, S., \& Leiserowitz, A. (2020). Social norms motivate COVID19 preventive behaviors. DOI: https://doi.org/10.31234/osf. io/9whp4

Gollwitzer, P. M. (1999). Implementation intentions: Strong effects of simple plans. American Psychologist, 54(7), 493503. DOI: https://doi.org/10.1037/0003-066X.54.7.493

Hamaker, E. L., Kuiper, R. M., \& Grasman, R. P. P. P. (2015). A critique of the cross-lagged panel model. Psychological Methods, 20(1), 102-116. DOI: https://doi.org/10.1037/ a0038889

Harper, C. A., Satchell, L. P., Fido, D., \& Latzman, R. D. (2020). Functional Fear Predicts Public Health Compliance in the COVID-19 Pandemic. International Journal of Mental Health and Addiction. DOI: https://doi.org/10.1007/s11469-02000281-5

Hertwig, R., \& Grüne-Yanoff, T. (2017). Nudging and Boosting: Steering or Empowering Good Decisions. DOI: https://doi. org/10.1177/1745691617702496

Hong, Y., \& Kim, S. (2020). Influence of Presumed Media Influence for Health Prevention: How Mass Media Indirectly Promote Health Prevention Behaviors through Descriptive Norms. Health Communication, 35(14), 1800-1810. DOI: https://doi.org/10.1080/10410236.2019.1663585

Hornik, R. (2002). Public Health Communication: Evidence for Behavior Change. Routledge. DOI: https://doi. org/10.4324/9781410603029 
Hu, L., \& Bentler, P. M. (1999). Cutoff criteria for fit indexes in covariance structure analysis: Conventional criteria versus new alternatives. Structural Equation Modeling: A Multidisciplinary Journal, 6(1), 1-55. DOI: https://doi. org/10.1080/10705519909540118

Janicke-Bowles, S. H., Raney, A. A., Oliver, M. B., Dale, K. R., Jones, R. P., \& Cox, D. (2019). Exploring the Spirit in U.S. Audiences: The Role of the Virtue of Transcendence in Inspiring Media Consumption. Journalism \& Mass Communication Quarterly, 1077699019894927. DOI: https://doi.org/10.1177/1077699019894927

Johnson, T., Dawes, C., Fowler, J., \& Smirnov, O. (2020). Slowing COVID-19 transmission as a social dilemma: Lessons for government officials from interdisciplinary research on cooperation. Journal of Behavioral Public Administration, 3(1). DOI: https://doi.org/10.30636/ jbpa.31.150

Kline, R. B. (2015). Principles and Practice of Structural Equation Modeling, Fourth Edition. Guilford Publications.

Kloeblen, A. S., \& Batish, S. S. (1999). Understanding the intention to permanently follow a high folate diet among a sample of low-income pregnant women according to the Health Belief Model. Health Education Research, 14(3), 327-338. DOI: https://doi.org/10.1093/her/14.3.327

Koch, J. (2002). The Role of Exercise in the African-American Woman with Type 2 Diabetes Mellitus: Application of the Health Belief Model. Journal of the American Academy of Nurse Practitioners, 14(3), 126-130. DOI: https://doi. org/10.1111/j.1745-7599.2002.tb00103.x

Koller, M. (2016). robustlmm: An R Package for Robust Estimation of Linear Mixed-Effects Models. Journal of Statistical Software, 75(1), 1-24. DOI: https://doi. org/10.18637/jss.v075.i06

Kollock, P. (1998). Social Dilemmas: The Anatomy of Cooperation. Annual Review of Sociology, 24(1), 183-214. DOI: https://doi.org/10.1146/annurev.soc.24.1.183

Kowalski, R. M., \& Black, K. J. (2021). Protection Motivation and the COVID-19 Virus. Health Communication, 36(1), 15-22. DOI: https://doi.org/10.1080/10410236.2020.1847448

Lin, Y., Hu, Z., Alias, H., \& Wong, L. P. (2020). Influence of Mass and Social Media on Psychobehavioral Responses Among Medical Students During the Downward Trend of COVID-19 in Fujian, China: Cross-Sectional Study. Journal of Medical Internet Research, 22(7), e19982. DOI: https://doi. org/10.2196/19982

Loewenstein, G. F., Weber, E. U., Hsee, C. K., \& Welch, Ned. (2001). Risk as Feelings. Psychological Bulletin, 127(2), 267286. DOI: https://doi.org/10.1037/0033-2909.127.2.267

Lunn, P. D., Belton, C. A., Lavin, C., McGowan, F. P., Timmons, S., \& Robertson, D. A. (2020). Using Behavioral Science to help fight the Coronavirus. Journal of Behavioral Public Administration, 3(1). DOI: https://doi.org/10.30636/ jbpa.31.147

Manganello, J., Bleakley, A., \& Schumacher, P. (2020). Pandemics and PSAs: Rapidly Changing Information in a New Media Landscape. Health Communication, 35(14),
1711-1714. DOI: https://doi.org/10.1080/10410236.2020. 1839192

Mantler, T. (2013). A systematic review of smoking Youths' perceptions of addiction and health risks associated with smoking: Utilizing the framework of the health belief model. Addiction Research \& Theory, 21(4), 306-317. DOI: https://doi.org/10.3109/16066359.2012.727505

Michie, S., van Stralen, M. M., \& West, R. (2011). The behaviour change wheel: A new method for characterising and designing behaviour change interventions. Implementation Science: IS, 6, 42. DOI: https://doi.org/10.1186/1748-59086-42

Müller, B. C. N., van Baaren, R. B., Ritter, S. M., Woud, M. L., Bergmann, H., Harakeh, Z., Engels, R. C. M. E., \& Dijksterhuis, A. (2009). Tell me why... The influence of selfinvolvement on short term smoking behaviour. Addictive Behaviors, 34(5), 427-431. DOI: https://doi.org/10.1016/j. addbeh.2008.12.016

Nexøe, J., Kragstrup, J., \& Søgaard, J. (1999). Decision on influenza vaccination among the elderly: A questionnaire study based on the Health Belief Model and the Multidimensional Locus of Control Theory. Scandinavian Journal of Primary Health Care, 17(2), 105-110. DOI: https:// doi.org/10.1080/028134399750002737

Park, T., Ju, I., Ohs, J. E., \& Hinsley, A. (2020). Optimistic bias and preventive behavioral engagement in the context of COVID-19. Research in Social and Administrative Pharmacy. DOI: https://doi.org/10.1016/j. sapharm.2020.06.004

Peters, E., Lipkus, I., \& Diefenbach, M. A. (2006). The Functions of Affect in Health Communications and in the Construction of Health Preferences. Journal of Communication, 56(s1), S140-S162. DOI: https://doi.org/10.1111/j.14602466.2006.00287.x

Peters, G.-J., \& Crutzen, R. (2018). Establishing determinant relevance using CIBER: An introduction and tutorial. The European Health Psychologist, 20(3), 484-494. DOI: https:// doi.org/10.31234/osf.io/5wjy4

R Core Team. (2019). R: A language and environment for statistical computing. Vienna, Austria: R Foundation for Statistical Computing. https://www.r-project.org/

Rimal, R. N., \& Storey, J. D. (2020). Construction of Meaning during a Pandemic: The Forgotten Role of Social Norms. Health Communication, 35(14), 1732-1734. DOI: https://doi. org/10.1080/10410236.2020.1838091

Rogers, R. W. (1975). A Protection Motivation Theory of Fear Appeals and Attitude Change1. The Journal of Psychology, 91(1), 93-114. DOI: https://doi.org/10.1080/00223980.197 5.9915803

Rosenstock, I. M., Strecher, V. J., \& Becker, M. H. (2016). Social Learning Theory and the Health Belief Model. Health Education Quarterly. DOI: https://doi. org/10.1177/109019818801500203

Ross, L., Greene, D., \& House, P. (1977). The "false consensus effect": An egocentric bias in social perception and attribution processes. Journal of Experimental 
Social Psychology, 13(3), 279-301. DOI: https://doi.

org/10.1016/0022-1031(77)90049-X

Royal Netherlands Meteorological Institute. (2020). Dagggevens van Het Weer in Nederland. https://www.knmi. nl/nederland-nu/klimatologie/daggegevens/

Satterthwaite, F. E. (1946). An Approximate Distribution of Estimates of Variance Components. Biometrics Bulletin, 2(6), 110-114. DOI: https://doi.org/10.2307/3002019

Schwarz, N. (2012). Feelings-as-Information Theory. In Handbook of Theories of Social Psychology (Vol. 1, pp. 289308). DOI: https://doi.org/10.4135/9781446249215.n15

Sheeran, P., Maki, A., Montanaro, E., Avishai-Yitshak, A., Bryan, A., Klein, W. M. P., Miles, E., \& Rothman, A. J. (2016). The impact of changing attitudes, norms, and self-efficacy on health-related intentions and behavior: A meta-analysis. Health Psychology, 35(11), 1178-1188. DOI: https://doi.org/10.1037/hea0000387

Simoski, B., Klein, M. C. A., Araújo, E. F. de M., van Halteren, A. T., van Woudenberg, T. J., Bevelander, K. E., Buijzen, M., \& Bal, H. (2020). Understanding the complexities of Bluetooth for representing real-life social networks. Personal and Ubiquitous Computing. DOI: https://doi.org/10.1007/s00779020-01435-x

Slovic, P., Finucane, M. L., Peters, E., \& MacGregor, D. G. (2004). Risk as Analysis and Risk as Feelings: Some Thoughts about Affect, Reason, Risk, and Rationality. Risk Analysis, 24(2), 311-322. DOI: https://doi.org/10.1111/ j.0272-4332.2004.00433.x

Smit, C. R., Bevelander, K. E., Leeuw, R. N. de, Burk, W. J., Buijs, L., Woudenberg, T. J. van, \& Buijzen, M. (in press). Promoting water consumption among Dutch children: An evaluation of the social network intervention Share $\mathrm{H}_{2} \mathrm{O}$. BMC Public Health.

Smit, C. R., Leeuw, R. N. de, Bevelander, K. E., Burk, W. J., Buijs, L., Woudenberg, T. J. van, \& Buijzen, M. (2020). Promoting water consumption among children: A three-arm cluster randomised controlled trial testing a social network intervention. Public Health Nutrition, 1-13. DOI: https://doi. org/10.1017/S1368980020004802

Storbeck, J., \& Clore, G. L. (2008). Affective Arousal as Information: How Affective Arousal Influences Judgments, Learning, and Memory. Social and Personality Psychology Compass, 2(5), 1824-1843. DOI: https://doi.org/10.1111/ j.1751-9004.2008.00138.x
Teck Ling, G. H., \& Chyong Ho, C. M. (2020). Effects of the Coronavirus (COVID-19) Pandemic on Social Behaviours: From a Social Dilemma Perspective Miscellaneous. Technium Social Sciences Journal, 7, 312-320. DOI: https:// doi.org/10.47577/tssj.v7i1.423

Valente, T. W. (2012). Network Interventions. Science, 337(6090), 49-53. DOI: https://doi.org/10.1126/ science. 1217330

Valkenburg, P. M., \& Piotrowski, J. T. (2017). Plugged In: How Media Attract and Affect Youth. Yale University Press. DOI: https://doi.org/10.12987/yale/9780300218879.001.0001

Van Woudenberg, T. J., Bevelander, K. E., Burk, W. J., Smit, C. R., Buijs, L., \& Buijzen, M. (2020). Testing a Social Network Intervention Using Vlogs to Promote Physical Activity Among Adolescents: A Randomized Controlled Trial. Frontiers in Psychology, 10. DOI: https://doi.org/10.3389/ fpsyg.2019.02913

von Elm, E., Altman, D. G., Egger, M., Pocock, S. J., Gøtzsche, P. C., \& Vandenbroucke, J. P. (2014). The Strengthening the Reporting of Observational Studies in Epidemiology (STROBE) Statement: Guidelines for reporting observational studies. International Journal of Surgery, 12(12), 1495-1499. DOI: https://doi.org/10.1016/j. ijsu.2014.07.013

Witte, K. (1992). Putting the fear back into fear appeals: The extended parallel process model. Communication Monographs, 59(4), 329-349. DOI: https://doi. org/10.1080/03637759209376276

Woudenberg, T. J. van, Bevelander, K. E., Burk, W. J., Smit, C. R., Buijs, L., \& Buijzen, M. (2020). Comparing the measurement of different social networks: Peer nominations, online communication, and proximity data. Network Science, 8(1), 62-78. DOI: https://doi.org/10.1017/nws.2019.65

Yeager, D. S., Dahl, R. E., \& Dweck, C. S. (2018). Why Interventions to Influence Adolescent Behavior Often Fail but Could Succeed. Perspectives on Psychological Science, 13(1), 101-122. DOI: https://doi. org/10.1177/1745691617722620

Yu, Q., \& Li, B. (2020a). Mlma: Multilevel Mediation Analysis. R package version 6.0-0. https://CRAN.R-project.org/ package $=\mathrm{mlma}$

Yu, Q., \& Li, B. (2020b). Third-variable effect analysis with multilevel additive models. PLOS ONE, 15(10), e0241072. DOI: https://doi.org/10.1371/journal.pone.0241072 
TO CITE THIS ARTICLE:

Rozendaal, E., van Woudenberg, T., Crone, E., Green, K., van de Groep, S., de Leeuw, R., Sweijen, S., \& Buijzen, M. (2021).

Communication and COVID-19 Physical Distancing Behavior Among Dutch Youth. Health Psychology Bulletin, 5(1), pp. 81-102. DOI: https://doi.org/10.5334/hpb.33

Submitted: 17 January 2021 Accepted: 20 May 2021 Published: 01 June 2021

COPYRIGHT:

(c) 2021 The Author(s). This is an open-access article distributed under the terms of the Creative Commons Attribution 4.0 International License (CC-BY 4.0), which permits unrestricted use, distribution, and reproduction in any medium, provided the original author and source are credited. See http://creativecommons.org/licenses/by/4.0/.

Health Psychology Bulletin is a peer-reviewed open access journal published by Ubiquity Press.

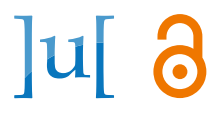

